\title{
Halokinetic modulation of sedimentary thickness and architecture: A numerical modelling approach
}

DOI:

10.1111/bre.12569

10.1111/bre.12569

\section{Document Version}

Final published version

Link to publication record in Manchester Research Explorer

\section{Citation for published version (APA):}

Cumberpatch, Z. A., Finch, E., Kane, I. A., Pichel, L. M., Jackson, C. A. L., Kilhams, B. A., Hodgson, D. M., \& Huuse, M. (2021). Halokinetic modulation of sedimentary thickness and architecture: A numerical modelling approach. Basin Research, 33(5), 2572-2604. https://doi.org/10.1111/bre.12569, https://doi.org/10.1111/bre.12569

\section{Published in:}

Basin Research

\section{Citing this paper}

Please note that where the full-text provided on Manchester Research Explorer is the Author Accepted Manuscript or Proof version this may differ from the final Published version. If citing, it is advised that you check and use the publisher's definitive version.

\section{General rights}

Copyright and moral rights for the publications made accessible in the Research Explorer are retained by the authors and/or other copyright owners and it is a condition of accessing publications that users recognise and abide by the legal requirements associated with these rights.

\section{Takedown policy}

If you believe that this document breaches copyright please refer to the University of Manchester's Takedown Procedures [http://man.ac.uk/04Y6Bo] or contact uml.scholarlycommunications@manchester.ac.uk providing relevant details, so we can investigate your claim.

\section{OPEN ACCESS}




\title{
Halokinetic modulation of sedimentary thickness and architecture: A numerical modelling approach
}

\author{
Zoë A. Cumberpatch ${ }^{1}$ (D) | Emma Finch ${ }^{1}$ | Ian A. Kane ${ }^{1}$ | Leonardo M. Pichel ${ }^{2}$ | \\ Christopher A.-L. Jackson $^{1}$ | Ben A. Kilhams ${ }^{3}$ | David M. Hodgson ${ }^{4}$ | Mads Huuse $^{1}$
}

${ }^{1}$ Department of Earth and Environmental Sciences, University of Manchester,

Manchester, UK

${ }^{2}$ Department of Earth Science, Bergen University, Bergen, Norway

${ }^{3}$ Shell Upstream International, London, UK

${ }^{4}$ The Stratigraphy Group, School of Earth and Environment, University of Leeds, Leeds, UK

\section{Correspondence}

Zoë A. Cumberpatch, Department of Earth, Atmospheric and Environmental Sciences, University of Manchester, Manchester, UK. Email: zoe.cumberpatch@manchester.ac.uk

\section{Funding information}

Natural Environment Research Council, Grant/Award Number: NEM00578X/1

\begin{abstract}
Subsurface salt flow can deform overlying strata and influence contemporaneous sedimentary systems. Studying salt-sediment interactions is challenging in the subsurface due to poor imaging adjacent to salt, and in the field due to the dissolution of halite. Discrete Element Modelling provides an efficient and inexpensive tool to model stratigraphy and deformation around salt structures, which is advantageous over other modelling techniques as it realistically recreates brittle processes such as faulting. Six 2D experiments were run representing 4.6 Myr to determine the effect of salt growth on syn-kinematic stratigraphy. Halokinetic deformation of stratigraphic architecture was assessed by varying sediment input rates through time. Results show the realistic formation and evolution of salt-related faults which define a zone of halokinetic influence ca. 3 times the width of the initial diapir. Outside of this, early diapiric and syn-kinematic stratigraphy are undeformed. Within this zone, syn-kinematic strata are initially isolated into primary salt withdrawal basins, onlapping and thinning towards the salt-cored high. In most models, syn-kinematic strata eventually thin across and cover the diapir roof. Thinning rates are up to six times greater within $350 \mathrm{~m}$ of the diapir, compared to further afield, and typically decrease upwards (with time) and laterally (with distance) from the diapir. Outputs are compared to a subsurface example from the Pierce field, UK North Sea, which highlights the importance of considering local fluctuations in diapir rise rate. These can create stratigraphic architectures that may erroneously be interpreted to represent increases/decreases in sedimentation rate. Exposed examples, such as the Bakio diapir, northern Spain, can be used to make inferences of the expected depositional facies, below model resolution. Our models aid the prediction of sedimentary unit thickness and thinning rates and can be used to test interpretations arising from incomplete or low-resolution subsurface and outcrop data when building geological models for subsurface energy.
\end{abstract}

\section{K E Y W O R D S}

halokinesis, numerical modelling, salt, stratigraphy, tectonics, tectonics and topography 


\section{1 | INTRODUCTION}

Salt tectonics influences over 120 sedimentary basins globally (e.g. Hudec \& Jackson, 2007). These basins include some of the world's largest subsurface energyproducing provinces, such as the Gulf of Mexico (e.g. Booth et al., 2003; Hudec et al., 2013), the North Sea (e.g. Charles \& Ryzhikov, 2015; Mannie et al., 2014, 2016; Stricker et al., 2018; Figure 1), offshore Angola (e.g. Doughty-Jones et al., 2017; Howlett et al., 2021; Oluboyo et al., 2014), offshore Brazil (e.g. Pichel et al., 2019; Rodriguez et al., 2018, 2020), and the Precaspian Basin (e.g. Duffy et al., 2017; Pichel \& Jackson, 2020). There is, therefore, a need to understand the interactions of sedimentary systems with topographic relief associated with salt tectonics, to provide insight into sediment routing patterns around topography (e.g. Cumberpatch, Kane, et al., 2021; Giles \& Lawton, 2002; Pichel \& Jackson, 2020; Ribes et al., 2015; Rowan et al., 2003). This approach can improve predictions of reservoir distribution, and trap geometry and style for carbon storage (e.g. Maia da Costa et al., 2019; Roelofse et al., 2019), geothermal energy (e.g. Andrews et al., 2020; Daniilidis \& Herber, 2017; Harms, 2015), and hydrocarbons (Figure 1; e.g. Hodgson et al., 1992; Jackson \& Hudec, 2017; Pichel \& Jackson, 2020).

Constraining the dynamic evolution of the sediment-salt interface through time and space remains challenging. Despite advances in the quantity and quality of 3D seismic reflection data, the salt-sediment interface remains difficult to image due to poor velocity control, steep to overturned bedding and near-diapir deformation (Figure 1; Jones \& Davison, 2014). Resolution issues caused by variable lithological distributions, both within the salt and its overburden, further complicate seismic reflection-based, subsurface analysis (Davison, Alsop, Birch et al., 2000; Jones \& Davison, 2014). This leads to uncertainty in the prediction of facies and thicknesses via seismic methods (Figure 1; e.g. Berton \& Vesely, 2016; Hossain, 2020).

Detailed depositional facies models of halokinetically influenced depositional systems (or portions of such systems) benefit from calibration with outcrop analogues (e.g. Banham \& Mountney, 2013a, 2013b, 2014; Cumberpatch, Kane, et al., 2021; Jackson \& Hudec, 2017; Lerche \& Petersen, 1995; Madof et al., 2009; Rodriguez et al., 2020), such that they can be more widely and confidently applied to salt-influenced basins globally. However, outcrop examples possess their own set of uncertainties; exposed examples are often limited in the rock record, largely due to the dissolution of halite forming the core of the salt bodies (Jackson \& Hudec, 2017). Rare exposures provide sub-seismic scale facies information for shallow- (e.g. Giles \& Lawton, 2002; Giles \& Rowan, 2012), deep- (e.g. Cumberpatch, Kane, et al., 2021; Poprawski et al., 2014, 2016) and non-marine stratigraphy (e.g. Banham \& Mountney, 2013a, 2013b, 2014;

\section{Highlights}

- We use a Discrete Element Model (DEM) to determine the effect of salt growth on stratigraphic architecture for different sedimentation rates and patterns.

- Results show realistic formation and evolution of salt-related faults which define a zone of halokinetic influence, outside of which stratigraphy are undeformed.

- Stratigraphy initially thins and onlaps' the salt cored structure and is isolated to individual minibasins, before being laterally extensive across the model but continuing to thin over the residual diapir's crest.

- Halokinetic modulation is up to six times more intense within $350 \mathrm{~m}$ of the diapir, compared to further afield, halokinetic influence is shown to reduce laterally and temporarily.

- The DEM results are compared to analogues from the Eastern Central Graben and Basque Cantabrian Basin.

Ribes et al., 2015, 2017). Many field examples are small in size compared to subsurface basins and therefore provide only small-scale details of, for example, sedimentary structures and stratal stacking patterns, rather than the larger, basin-scale tectonostratigraphic context of salt-sediment interactions provided by integrated subsurface datasets. While useful, each subsurface or field example represents a unique record of the ratio of relative salt rise and sedimentation rate. Also, subsurface and field examples provide only one snapshot in time (Figure 1). Physical models have an advantage in recreating the evolution of specific subsurface analogues (Dooley \& Hudec, 2017; Dooley et al., 2013, 2015, 2020; Ferrer et al., 2017; Roma et al., 2018) and studying sediment gravity flow distribution and evolution adjacent to salt topography (Gaullier \& Vendeville, 2005; Sellier \& Vendeville, 2009; Soutter et al., 2021).

A number of remaining questions can be addressed by taking a numerical modelling approach that allows us to modify and isolate the key controls on salt-sediment interactions. These include: (a) How does salt topography influence depositional systems, and thus depositional facies, and how does this vary laterally and temporally? (b) How do unconformities, onlap contacts, and faults and fractures vary in salt-influenced settings? (c) How does sedimentation rate influence the width of the roof and basin salt-related deformation zones? and (d) How do stratigraphic thinning rates 


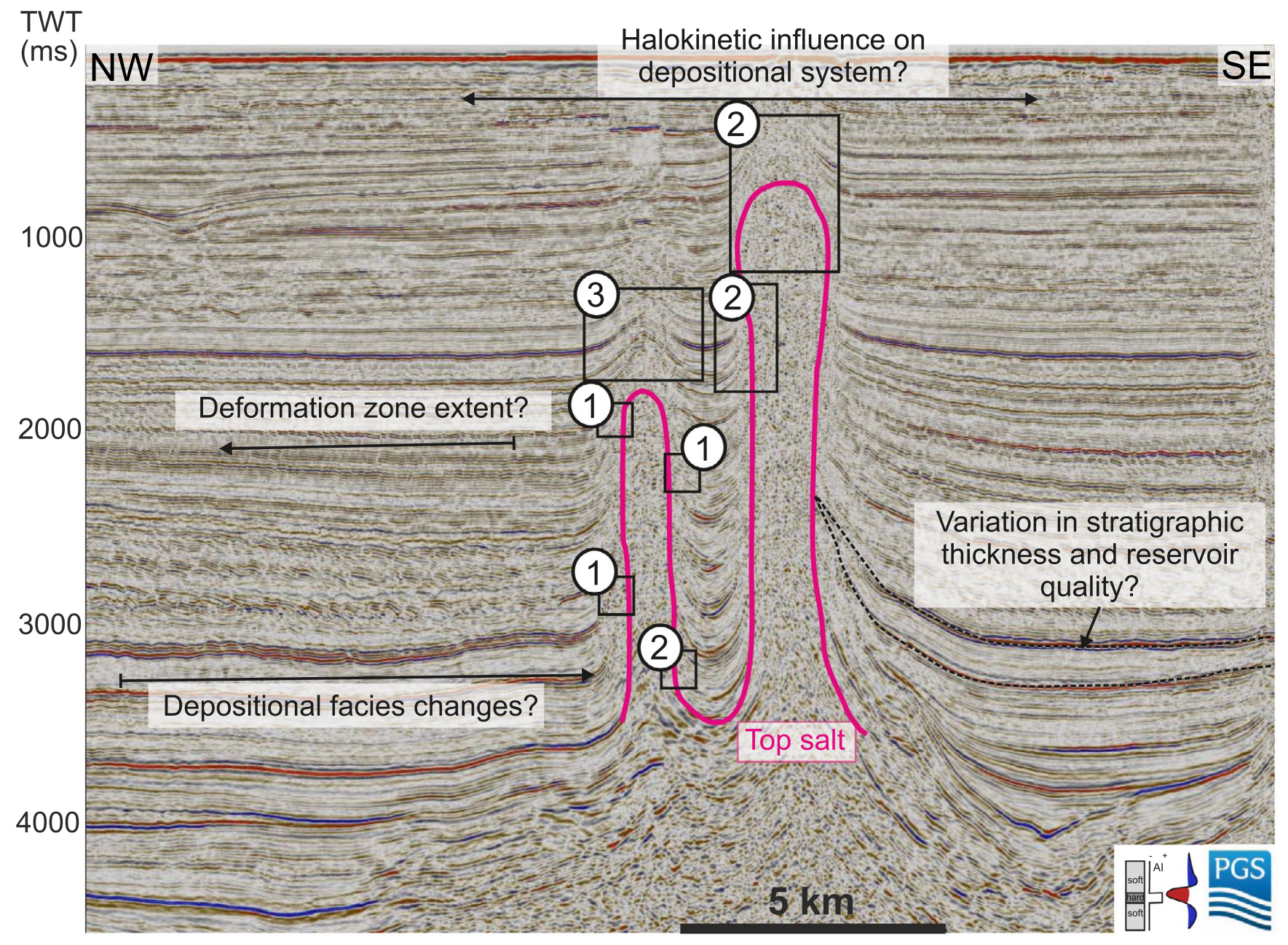

FI G U R E 1 Seismic reflection cross-section from the Pierce diapirs, Eastern Central Graben, UK North Sea (located in Figure 10) highlighting some of the key questions and uncertainties of subsurface interpretation in salt-influenced basins. Mapping top salt, visualising pinch outs and onlap geometries in areas of lower-quality data adjacent to the salt (1), confidently mapping top salt (2), and studying the lateral and vertical extent of syn-kinematic deformation and sedimentation (3), are challenging. Seismic data courtesy of PGS (MegaSurvey Plus 3D seismic data)

associated with salt growth vary with sedimentation rate and distance from the salt structure?

Most recent advances in the numerical modelling of saltrelated deformation use finite element models (FEM), which are based on continuum methods. Such studies have focused on the physical conditions required for the initiation and development of diapirism (Chemia et al., 2008; Fernandez \& Kaus, 2015; Fuchs et al., 2011; Gemmer et al., 2004, 2005; Hamilton-Wright et al., 2019; Nikolinakou et al., 2017; Peel et al., 2020; Poliakov et al., 1993), the stratigraphic architecture of subsiding minibasins (Fernandez et al., 2020; Sylvester et al., 2015; Wang et al., 2017), reconstructing the evolutionary history of salt-affected stratigraphy (Ismail-Zadeh et al., 2001, 2004; Pichel et al., 2017, 2019), and salt-related stress (and strain) analysis (Heidari et al., 2017; Luo et al., 2012, 2017; Nikolinakou et al., 2012, 2014a, 2014b, 2018). FEM treats the overburden as a continuous frictional-plastic or viscous-plastic material, which prevents the development of realistic brittle deformation, for example, fracturing and faulting, in overburden stratigraphy (Figure 1). Most FEM packages currently have limited capacity to generate faults during simulations, and therefore either have no faults, or faults that are pre-defined at the start of the model simulation (e.g. Heidari et al., 2016; Nikolinakou et al., 2014a, 2018). FEM is, however, advantageous for studying ductile deformation and salt flow dynamics (Albertz \& Ings, 2012).

Discrete Element Models (DEM), which essentially treat the contact between each element as a slip surface, are able to replicate spontaneous, realistic, localised fault nucleation and growth (Cumberpatch et al., 2021; Pichel et al., 2017, 2019) and are therefore appropriate for studying the interactions between salt-related topography, sedimentation, and stratigraphic evolution. DEMs do have limitations, including the need for careful calibration of element parameters (Abe et al., 2011; Botter et al., 2014) and the limited number of elements and duration of simulations (Zhu et al., 2008). 
Despite this, DEM provides a quick, efficient and inexpensive method to investigate system evolution through time (Allen \& Tildesley, 1987; Donzé et al., 1994; Finch et al., 2003, 2004). It is, therefore, possible to test several scenarios and collect structural growth and syn-kinematic sediment thinning rate data during deformation. This helps to improve the recognition of the processes involved with salt-sediment interactions. DEM studies have recently been adapted to salt tectonics so that elements representing salt behave as viscous-plastic materials (Pichel et al., 2017, 2019).

Here, we use a DEM approach to understand how sedimentation rate affects stratal geometries in salt basins experiencing diapirism (Figure 1). First, we generate a baseline model with no sediment fill, to determine the effect of salt growth on the early diapiric 'overburden' sequence. For consistency in terminology, in line with recent work (Cumberpatch, Finch, et al., 2021), we define the 'early diapiric sequence' as the layers deposited prior to our simulation; they are discordant to the diapir and thus represent the earlier syn-kinematic strata related to an initial phase of diapirism that is assumed to have emplaced the diapir into our model (Jackson \& Hudec, 2017). We then vary sedimentation rates and patterns to study how these control the stratigraphic record of halokinesis in the later 'syn-kinematic' stratigraphy. The aims of this study are to: (a) investigate variable syn-kinematic sedimentation rates adjacent to a dynamic salt diapir using a DEM; (b) quantify near-diapir thinning rates and how this is controlled by varying sedimentation rates and patterns; and (c) compare the results to subsurface and field analogues to test the validity of our approach and our model predictions.

\section{2 | DATA AND METHODS}

The DEM applied here is a discontinuous numerical method, which derives from the Particle Dynamics Method and Lattice Solid Model (Mora \& Place, 1993, 1994). DEMs have been successfully used in physics and chemistry to study liquid and gas behaviours (Allen \& Tildesley, 1987). In geoscience, DEMs have been applied in two- and threedimensions (Deng et al., 2018; Finch \& Gawthorpe, 2017; Longshaw et al., 2009) to forecast geological hazards, often associated with mining (Benseghier et al., 2020; Cil \& Alshibli, 2012; Lu et al., 2014; Thoeni et al., 2014; Zhao et al., 2016), to investigate deformation caused by faulting and folding (Abe \& Urai, 2012; Belheine et al., 2009; Donzé et al., 1994; Finch, 1998; Finch et al., 2003, 2004; Hardy \& Finch, 2005, 2006; Imber et al., 2004; Katz et al., 2014; Longshaw et al., 2012; Schöpfer et al., 2006), and to study regional-scale salt tectonics (Pichel et al., 2017, 2019).

DEMs offer advantages over other numerical methods in that scale is not a restriction, complex re-meshing is not required, and results are easily reproducible. DEMs are fundamentally discontinuous, and therefore each element simulates the specific physical properties of a given rock. These conditions make it a fit-for-purpose method to quantitatively study syn-kinematic deformation.

DEM treats objects as assemblages of circular elements, connected by breakable elastic bonds through a 'repulsive-attractive' force. Elements remain bonded until their breaking separation (defined as the relative strength of the assemblage) is exceeded (Donzé et al., 1994; Finch et al., 2004). Once these bonds break, previously connected elements experience no further 'attractive' force, if these elements return to contact with each other a 'repulsive' force acts between them, preventing the healing of bonds (Finch et al., 2003, 2004; Hardy \& Finch, 2006). Motion of elements is frictionless and cohesionless with elastoplastic behaviour (Finch et al., 2003; Hardy \& Finch, 2006). Forces are resolved in the $x$ and $y$ directions and elements are subject to gravity $\left(F_{g}\right)$ (Finch et al., 2003). The equations that define the inter-relationship of all forces acting on the DEM are:

$$
\begin{gathered}
F_{x}=F_{i, n}-V \dot{X} \\
F_{y}=F_{i, n}-V \dot{Y}+F_{g}
\end{gathered}
$$

where $F_{i, n}$ corresponds to the total elastic force acting on an element, $V$ represents the viscosity and $\dot{X}$ and $\dot{Y}$ correspond to the velocity of the element in the $x$ - and $y$-directions. A viscous term is added to counteract the elastic behaviour within a closed system, making it ideal for studying quasisteady state tectonic processes (Finch et al., 2004; Pichel et al., 2017, 2019). For a comprehensive description of the equations governing DEM, see Mora and Place (1994), Finch et al. (2003, 2004), and Hardy and Finch (2005, 2006).

Pichel et al. $(2017,2019)$ recently used a DEM to model salt tectonics for the first time, studying regional-scale compressional salt tectonics (Pichel et al., 2017), and the effect of base salt relief on salt flow and overburden deformation styles (Pichel et al., 2019). Cumberpatch, Finch, et al. (2021) adapted these to focus on the modulation of stratigraphy by salt diapir growth. In these models, the elements representing salt were adjusted so they behave as a viscous-plastic material in order to represent rock-salt (Pichel et al., 2017, 2019). This requires inter-element interactions to be adjusted so they behave macroscopically as viscous-plastic materials and deform microscopically by dislocation creep, which is expected for dry rock salt (Pichel et al., 2017, 2019; Spiers et al., 1990). This does not naturally scale to completely reproduce salt, which typically deforms on a spectrum of mechanisms including diffusion and dislocation creep (Jackson \& Hudec, 2017; Pichel et al., 2017; Spiers et al., 1990), and usually contains 
traces of brines (Warren, 1999, 2006), but is considered a satisfactory assumption for studying salt tectonics. Pichel et al. (2017) tested breaking separations using biaxial compression tests. Values representing tenths of a model unit (e.g. 0.05) develop defined fault segments, and produced responses typical of brittle materials; these values are, therefore, used to represent overburden sediment in this study. Values representing hundredths of a unit (e.g. 0.001), however, show a minor elastic component (e.g. $F_{i}, \alpha \approx 0$ ), representing ductile viscous-plastic materials that accumulate strain without significant stress variations. Consequently, a breaking separation of 0.001 for salt elements is used in this study (see also Pichel et al., 2017), and other physical (Spiers et al., 1990) and numerical (Li \& Urai, 2016) experiments of salt deformation. By this value, we ensure salt element motion is entirely controlled by the viscosity and gravity of the system (viscous-plastic behaviour). The scaled viscosity of the salt is $1.1 \times 10^{9} \mathrm{~Pa} \mathrm{~s}$, which is lower than its real-world viscosity $\left(10^{17}-10^{18} \mathrm{~Pa} \mathrm{~s}\right.$ ) (Hudec \& Jackson, 2007; Jackson \& Hudec, 2017), but works as a reasonable approximation when compared with physical models (e.g. Dooley et al., 2009, 2012; Vendeville et al., 1995).

The modelled media in this study consists of a simulated $4.5 \mathrm{~km}$ by $1.5 \mathrm{~km}$ box, to ensure that the outer boundaries do not influence the structural evolution of the model centre. The media consist of an undeformable base and ca. 44,500 elements with varying radii (0.175-0.35 units, representing 5.25-9.75 m); these are randomly distributed to reduce failure in preferential orientations within the matrix. A 150 m-thick salt layer is overlain by nine coloured $150 \mathrm{~m}$ thick early diapiric overburden layers. A salt density of $2.2 \mathrm{~g} / \mathrm{cm}^{3}$ is used, to mimic a slightly impure halite composition, comparable to many global salt basins (e.g. Grant et al., 2019; Hudec \& Jackson, 2007; Jackson
\& Hudec, 2017; Warren, 1999, 2006) and previous models (Cumberpatch, Finch, et al., 2021; Pichel et al., 2017, 2019).

We do not investigate the initial stages of diapir evolution, which have been well-studied elsewhere (Costa \& Vendeville, 2002; Hudec \& Jackson, 2007; Trusheim, 1960; Vendeville \& Jackson, 1992), and instead, focus on late stage diapir growth. Therefore, we simplify a complicated three-dimensional process into a two-dimensional model, where we assume a linear salt wall or radially symmetric diapir was emplaced by an earlier phase of diapirism; such an assumption is used in other numerical (Pichel et al., 2017, 2019) and physical models (Davison et al., 1993; Dooley et al., 2009, 2012). This allows us to focus on the coupled deformation-sedimentation characterising the late stage of diapir growth, when a tall pre-existing diapir may be rejuvenated by compression (not modelled here) or rise due to buoyancy. During the experiment, the diapir is assumed to grow by passive diapirism (initially by halokinetic active rise; Rowan \& Giles, 2021), driven by the pressure of the overburden on the salt source layer and to a lesser extent by the density difference between the salt and the overlying stratigraphy (Jackson \& Hudec, 2017). Such growth can happen in the absence of regional tectonics, although mild far-field compression or extension, which can enhance deformation rates, are likely in most natural settings (Jackson $\&$ Hudec, 2017). Active rise is retarded by roof thickness and strength, and salt viscosity. Therefore, diapir height must be $>66 \%-75 \%$ of the surrounding overburden thickness for substantial halokinesis to occur and the roof thickness must be $<750 \mathrm{~m}$ (Schultz-Ela et al., 1993). In adhering to this rule, we invoke an individual sinusoid, $750 \mathrm{~m}$ (base width) wide, $1,050 \mathrm{~m}$ (70\% of the 1,500 m overburden) tall diapir and thus a $450 \mathrm{~m}$ roof (Figure 2). The diapir geometries

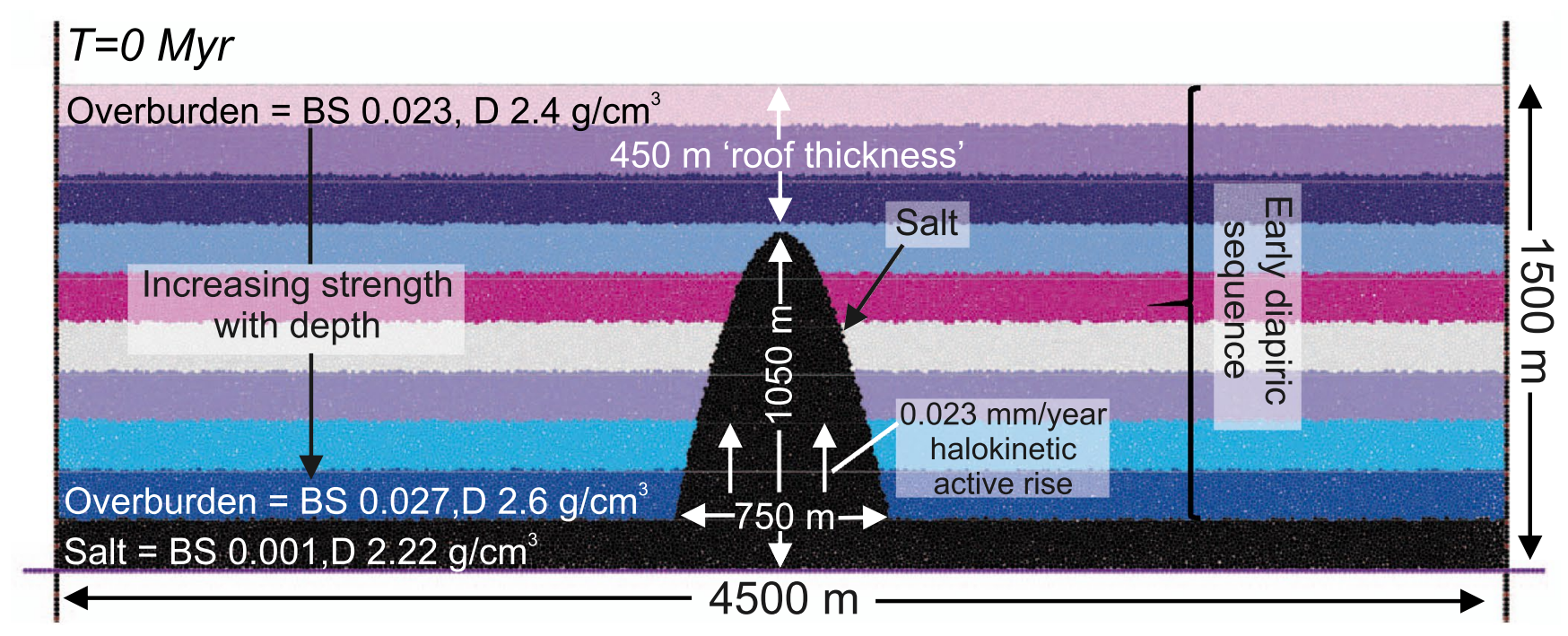

F I G U RE 2 Initial set up of the DEM $(T=0)$ and key parameters. Initial geometry and rise rates taken from North Pierce diapir (Davison, Alsop, Birch, et al., 2000). See text for discussion and Table 1 and Table S1 for further details. BS; Breaking separation (relative strength) 

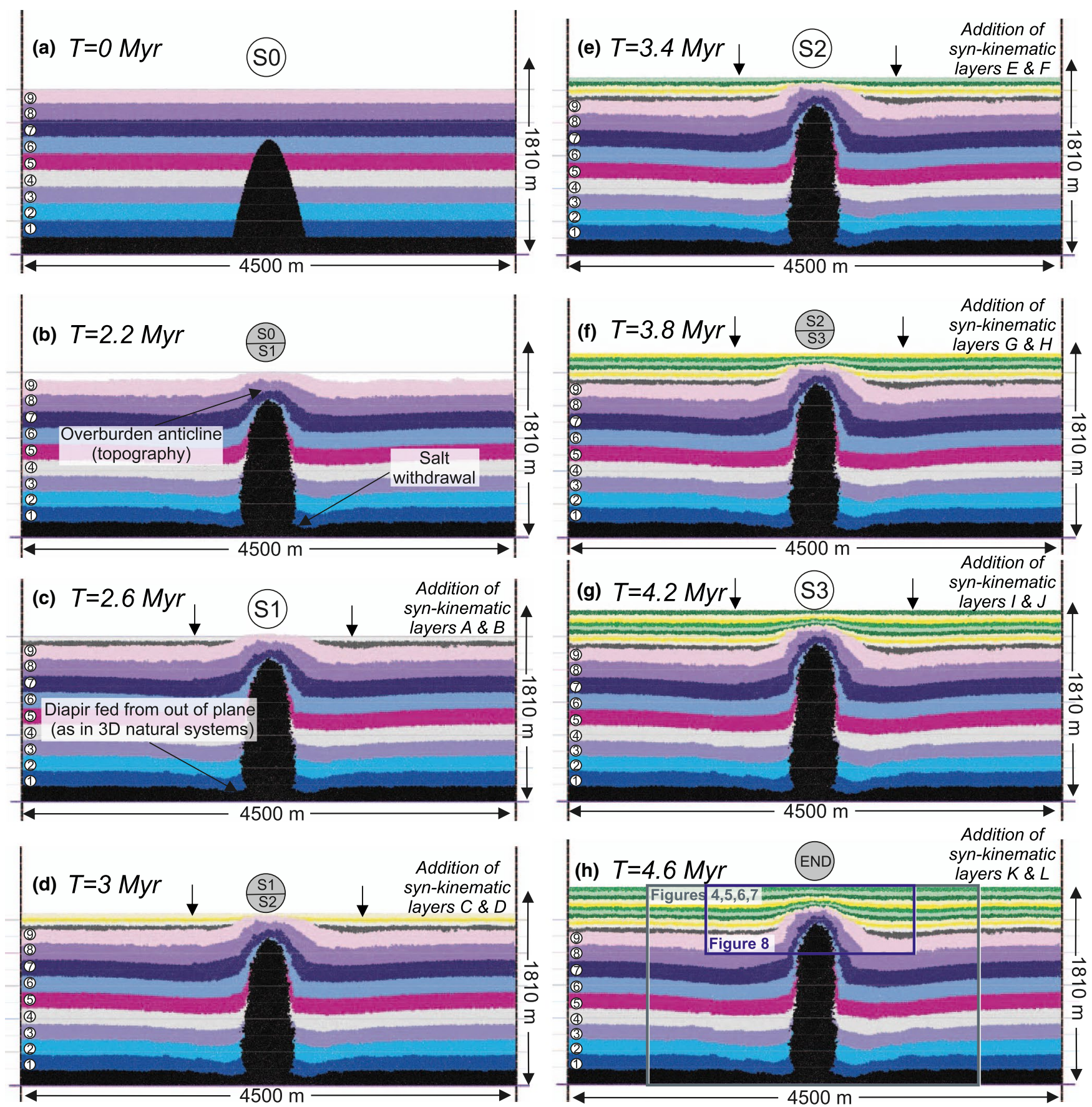

FIG URE 3 Model 3, the intermediate aggradation experiment with a sedimentation rate of $0.3 \mathrm{~mm} /$ year. Diapir growth rate is continuous and constant throughout $(0.023 \mathrm{~mm} / \mathrm{year})$. Outputs begin at the start of the experiment during a stage of no sedimentation ( $T=0 \mathrm{Myr}$, circle S0 (sedimentation stage 0)). At $T=2.2 \mathrm{Myr}$ (b) the diapir has generated surface topography and sedimentation begins to be added (S0/S1). Subsequent outputs are generated at $0.4 \mathrm{Myr}$ intervals across the three equal stages of sedimentation (open circles S1-S3) from 2.2 to 4.6 Myr. Active sediment input is constant in stages 1-3 and the boundaries are highlighted by the grey circle (e.g. $T=3 \mathrm{Myr}$ represents the end of sedimentation 1 and the beginning of sedimentation event 2). The final output is at 4.6 Myr (h), following the final sedimentation from S3. Due to minimal deformation in the outer section of all models, for clarity, subsequent figures will focus on only the central 3,000 m around the diapir (shown by the grey outline, $T=4.6 \mathrm{Myr}$ ). Subsequent figures are shown at $T=4.6(\mathrm{~h})$

used in our models are comparable to those observed in natural examples (Davison, Alsop, Evans et al., 2000; Jackson \& Hudec, 2017). Overburden breaking separation (relative strength) increases with depth linearly from 0.023 to 0.027 , representing increasing rock strength with depth. An overburden density of $2.4-2.6 \mathrm{~g} / \mathrm{cm}^{3}$ is used, similar to natural and modelled examples and increases with depth (e.g. Dooley et al., 2009, 2012; Fuchs et al., 2011). 
TABLE 1 Details of the different sedimentation patterns and rates used in the six experiments

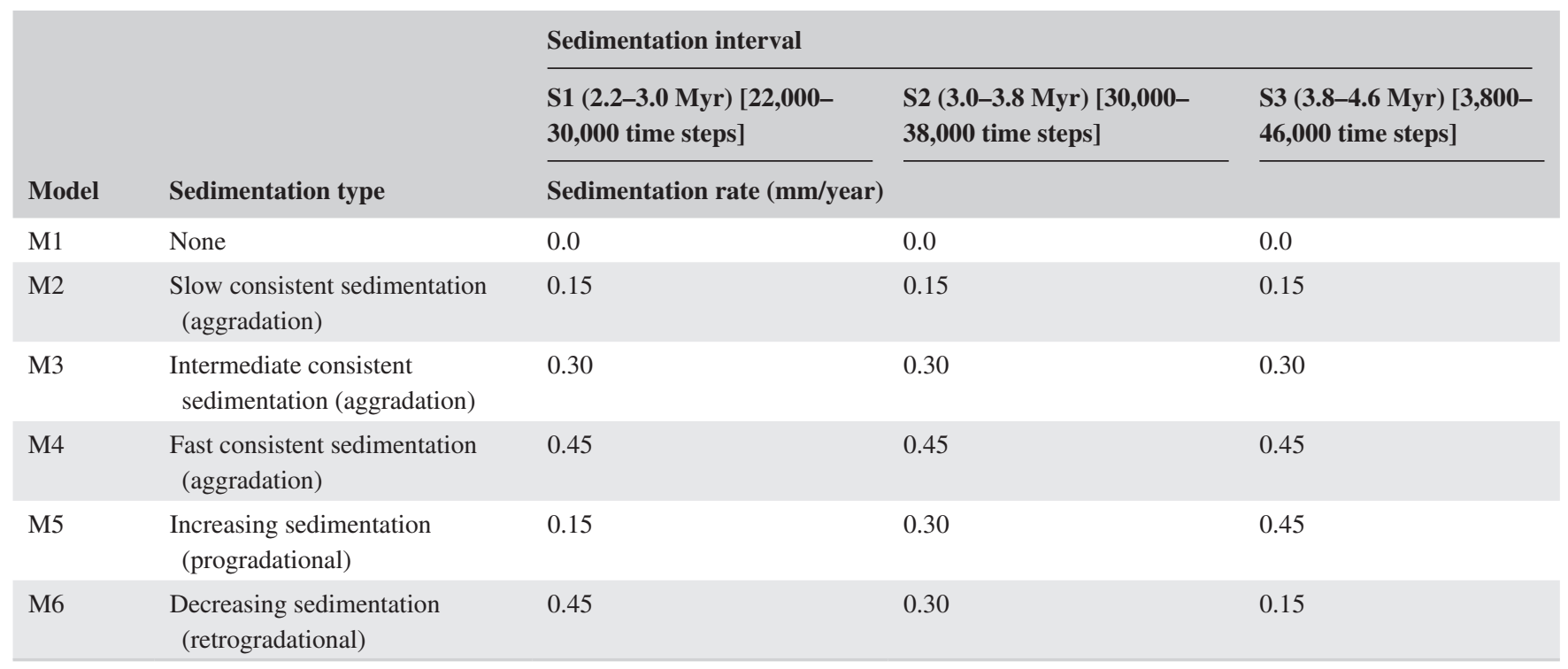

Note: $\mathrm{S} 1-\mathrm{S} 3$ refer to sedimentation intervals.

In nature, diapir growth periods are hugely variable in duration, ranging from 100,000s of years to 100 s of millions of years (Jackson \& Hudec, 2017). Our focus on the latestage of diapir growth and using seismic stratigraphic observations from natural examples (Grimstad, 2016; Oluboyo et al., 2014) and run times of previous numerical models (Pichel et al., 2017, 2019), supports our experimental run times of 46,000 timesteps with a timestep equivalent to 100 years (4.6 Myr in total). We impose an upwards motion of $0.023 \mathrm{~mm} / \mathrm{year}$, based on North Sea diapirs (Davison, Alsop, Birch et al., 2000) to all elements representative of salt to mimic diapir growth rate (Figure 2); this aims to replicate the volumetric salt supply rate $(\mathrm{Q})$ described by Peel et al. (2020). The diapir grows for 2.2 Myr (22,000 time steps) to allow the model to equilibrate creating seabed or surface topography, prior to the addition of sediment (Figure 3).

Sediment is added from 2.2 Myr with a constant density of $2.3 \mathrm{~g} / \mathrm{cm}^{3}$, in agreement with natural examples of near seabed sediment (Rider \& Kennedy, 2018; Tenzer \& Gladkikh, 2014) and a breaking separation of 0.023. Sediment is added in three $0.8 \mathrm{Myr}(8,000$ time steps) stages ( $\mathrm{S} 1-\mathrm{S} 3$, Table 1). Sedimentation rates in nature are extremely variable (Sadler, 1981). Here, the sedimentation rate was varied between 0.15 and $0.45 \mathrm{~mm} /$ year to match Cenozoic rates measured in the North Sea (de Haas et al., 1996) and the North Atlantic (Whitman \& Davies, 1979).

We present results from six experiments: a baseline zero sedimentation model, and five models with variable sedimentation rates and patterns (slow, intermediate and fast constant sedimentation, increasing and decreasing). Increasing and decreasing sedimentation rates are used to replicate the local advance and retreat of depositional sedimentary systems (progradation and retrogradation). Model set-up and parameters have been rigorously tested (Finch et al., 2003, 2004; Pichel et al., 2017, 2019) and are summarised in Table S1.

\subsection{Model limitations}

In addition to considering how modelled rock properties (density, viscosity, breaking separation; Table S1) scale to nature it is important to note that these values are often an oversimplification as they assume homogeneity in a given rock property for an entire layer (e.g. 4,500 m laterally or the entire $1,050 \mathrm{~m}$ tall diapir). The natural heterogeneity within stratigraphy, driven by depositional facies variability, differential diagenetic processes and products, and proximal to distal trends, are not incorporated in our models, which aim to replicate non-unique stratigraphic variations rather than specific, subtle, unique changes in depositional character. The complex three-dimensional processes occurring in salt basins are simplified into a two-dimensional model for this study. Therefore, we assume our models represent a cross-section through a three-dimensional linear salt wall or radially symmetric diapir (e.g. Cumberpatch, Finch, et al., 2021; Pichel et al., 2017, 2019); this is an oversimplification based on the complex, often asymmetric, geometries of salt structures (Hudec \& Jackson, 2007), but allows for the assumption that salt is continuously flowing in two dimensions, essentially being fed from out of the twodimensional plane (Tvedt et al., 2013, 2016; Vendeville et al., 1995). Modelling in two dimensions also assumes that all processes (such as salt withdrawal and stratigraphic bed rotation) are equal in all directions, which is 

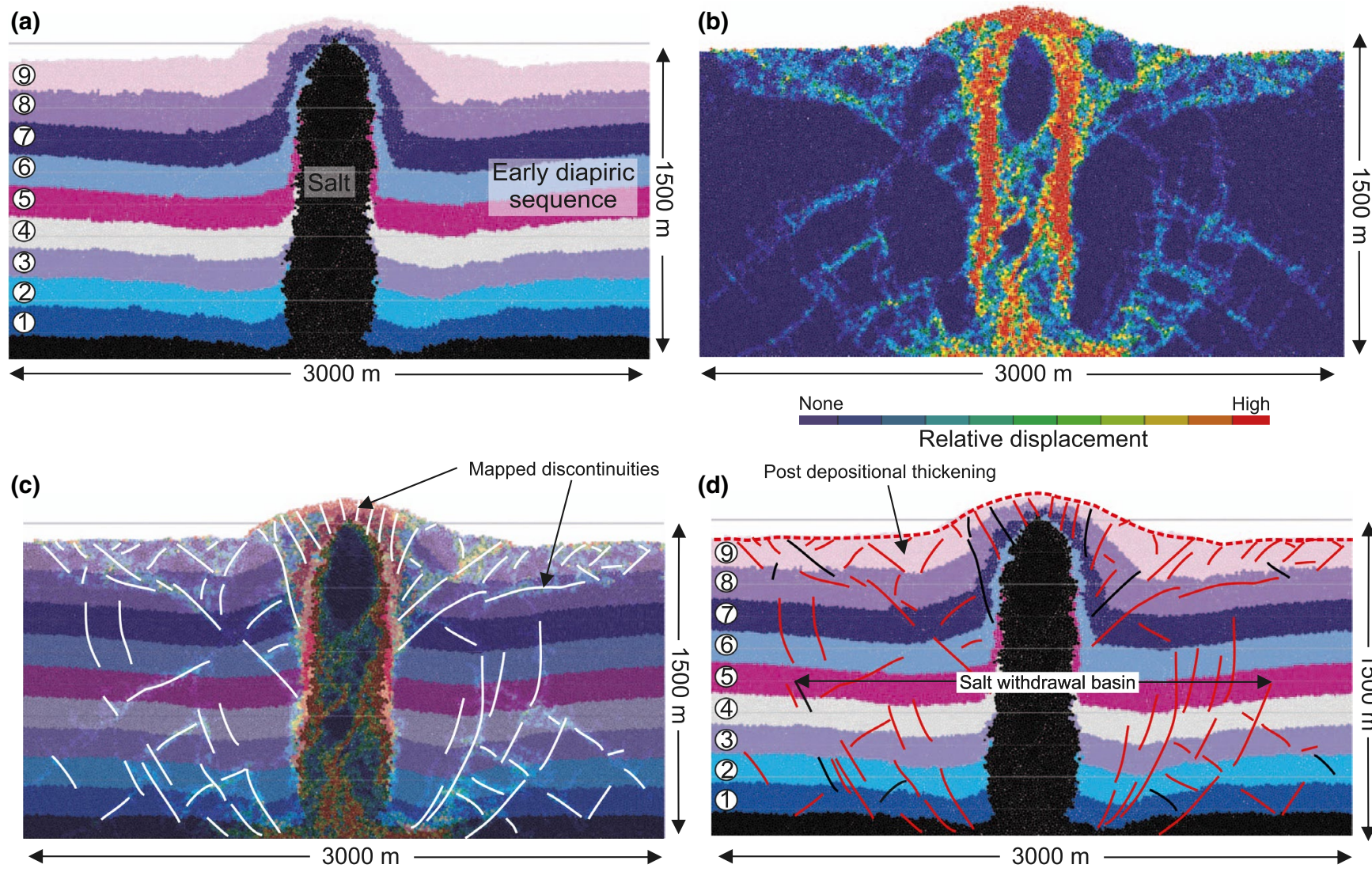

(d)

Relative displacement

Post depositional thickening

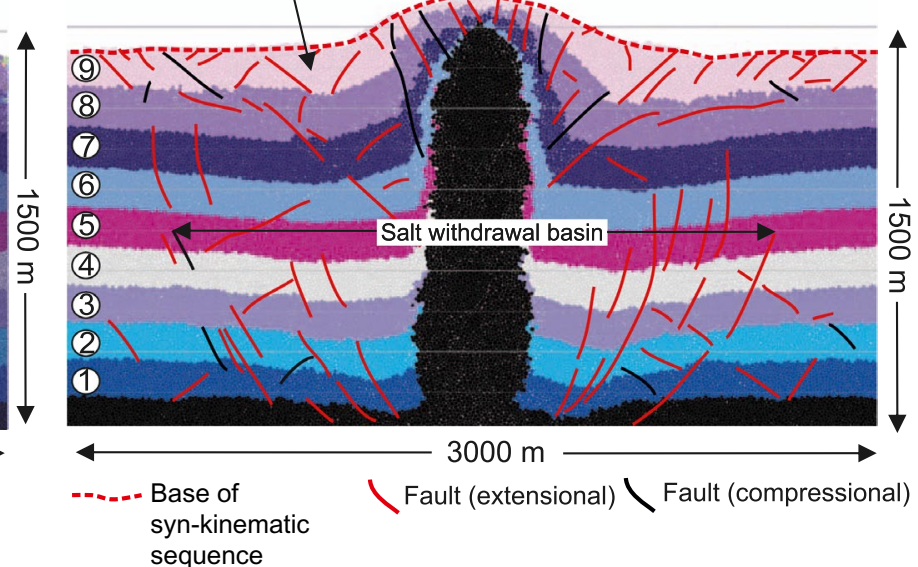

F I G U RE 4 M1, the model with no sedimentary fill, after 4.6 Myr. Displayed outputs represents the central 3,000 m of the original output model (located in Figure 3). (a) Model output, uninterpreted, early diapiric layers are numbered for clarity, and ease of subsequent discussion. (b) Static image of element displacement relative to initial neighbours for M1 after 4.6 Myr (provided for M1-M6 in Figure S2). Cold colours represent elements that are in contact with their original neighbour and hot colours indicate high displacement. This is used to show discontinuities and is a proxy for fault location. (c) (a) overlain with (b), interpreted with locations of discontinuities, highlighting the methodology used to interpret structures for all models. Note how the majority of the internal salt has remained in connection with its original neighbouring element and the radial faults are associated with salt withdrawal. The maximum displacement shows the relative movement of the salt, the neighbouring overburden, and the high mobility of layers in close proximity to the diapir. Note the lack of deformation outside of the salt withdrawal basin. (d) Interpreted static DEM for 4.6 Myr, faults are taken from discontinuities in (c), and overlain onto (a)

an oversimplification (e.g. Dutta et al., 2016; Ismail-Zadeh et al., 2004; Jackson \& Hudec, 2017; Mattson et al., 2020; Pichel \& Jackson, 2020). However, this is a suitable assumption in simple models that focus primarily on the role of sedimentation rate variability on the halokinetic depositional record. In order to prevent circular reasoning, our model inputs do not attempt to recreate a specific realworld diapir, but rather a simplified universally applicable structure. The absence of more complicated salt geometries (e.g. salt overhangs or welds) prevents direct comparison of the models to specific settings with complicated threedimensional salt structures (e.g. the Gulf of Mexico). However, our approach allows us to generate more general, possibly portable insights that are applicable to global salt basins. Finally, sedimentation rates are extremely variable and non-linear (Sadler, 1981); thus, when comparing to certain analogues, 'slow' and 'fast' sedimentation (stated in Table 1) should be taken as relative rates rather than absolute values. Sediments can be deposited above the diapir relief, suggesting that they are applicable to subaqueous settings, and are assumed to aggrade evenly, preventing direct comparison to deltaic systems (clinoforms).

\section{3 | RESULTS}

The model with an intermediate sedimentation rate (M3) is first presented (Figure 3) to examine the relationship between the rates of salt diapir rise and sedimentation. Subsequent sections describe and compare diapir growth, deformation and stratigraphic architectures across all models (Figures 4-8; Tables 2 and 3). 
(a)

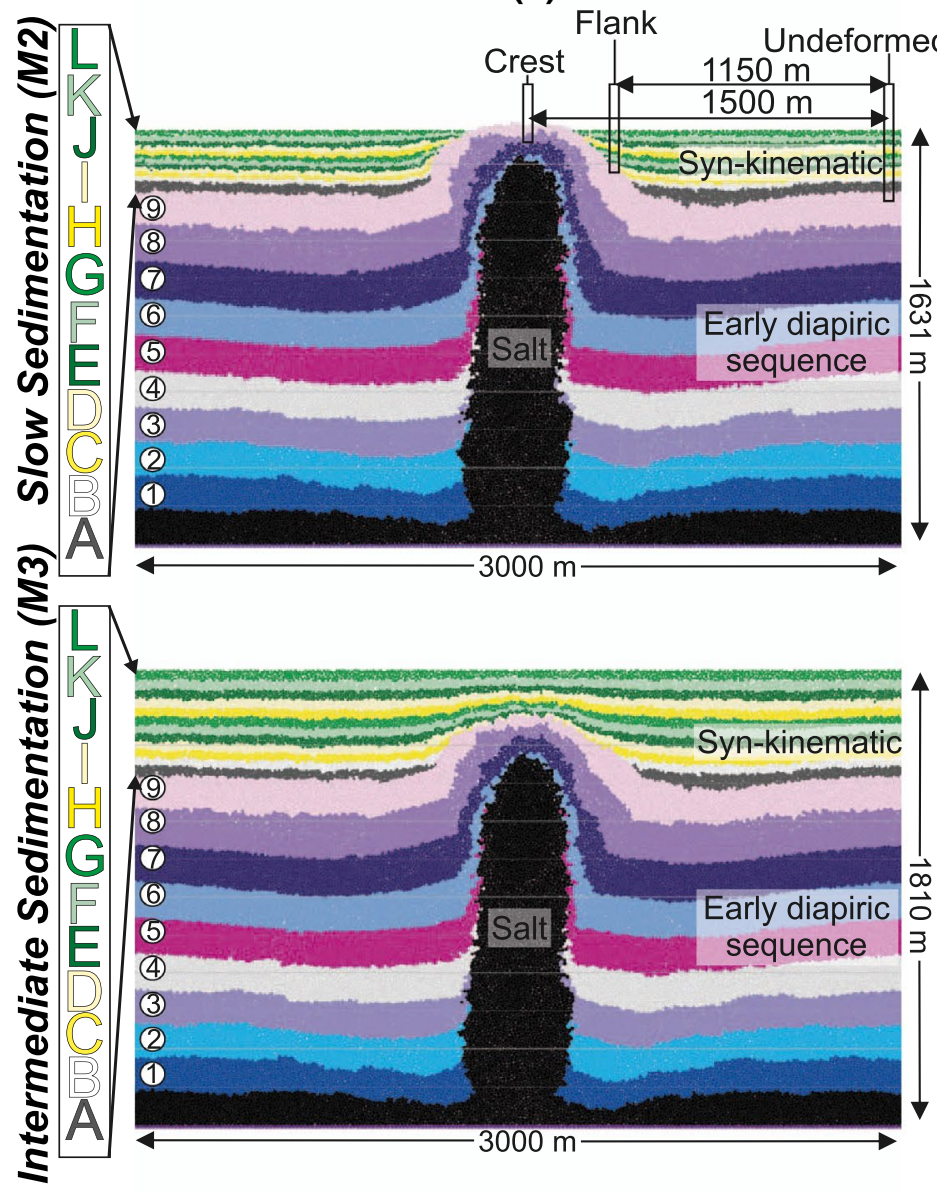

(b)
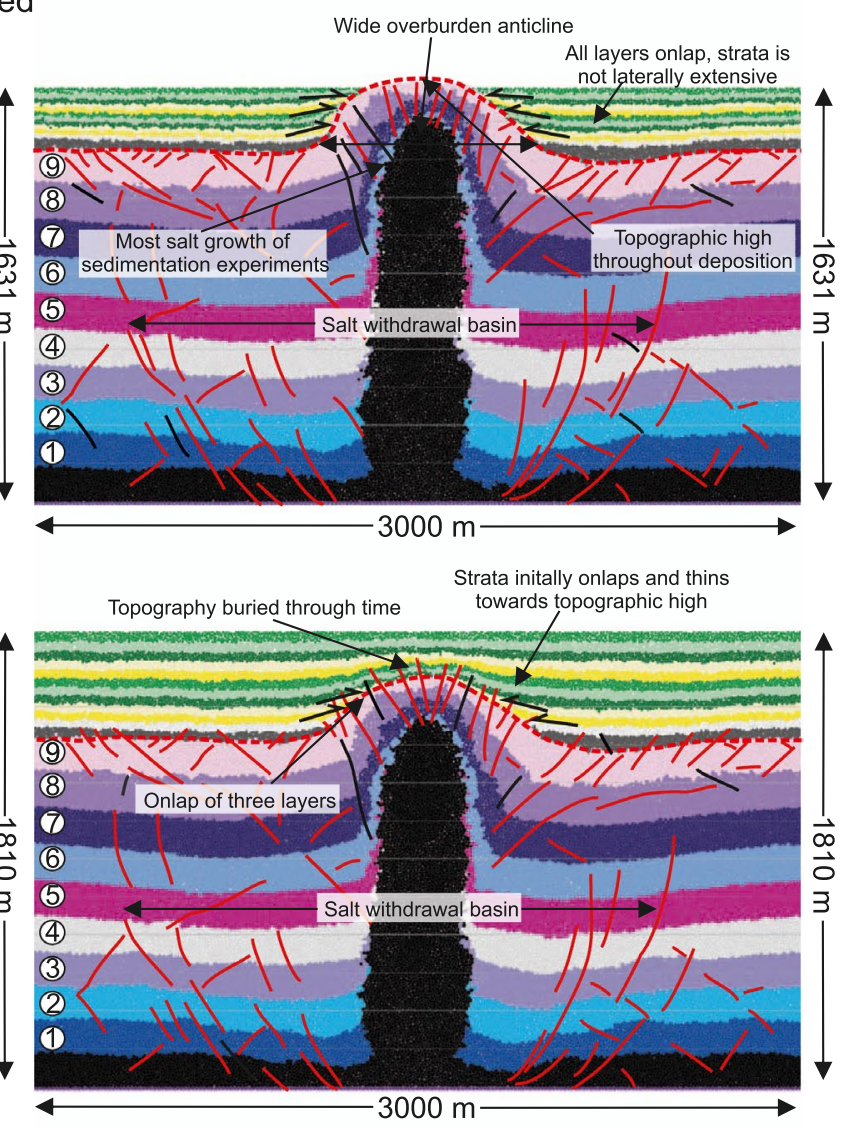
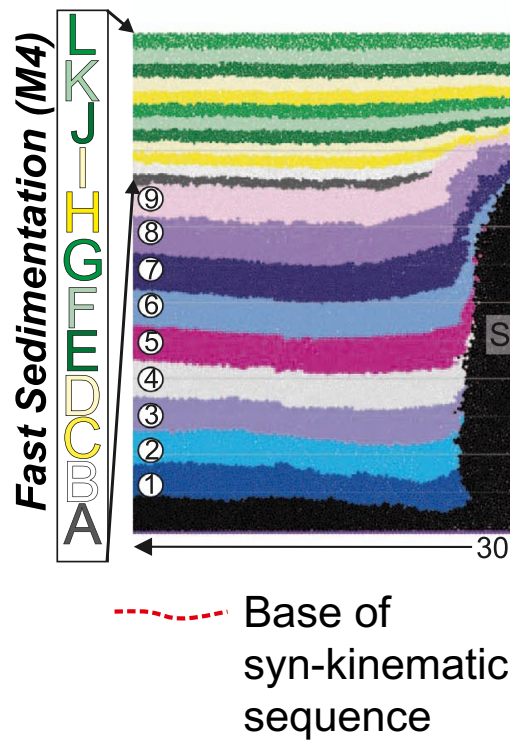

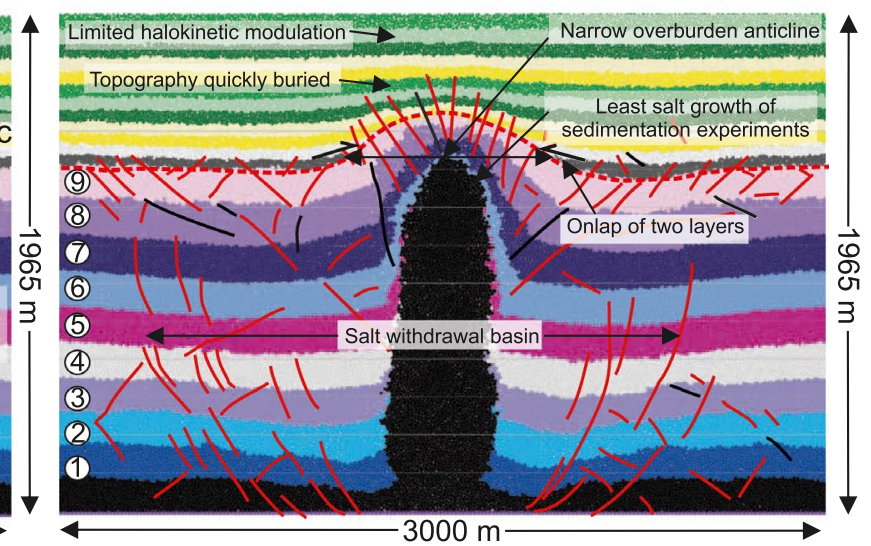

Fault (extensional) \Fault (compressional) $\longrightarrow$ Onlap

F I G U RE 5 Uninterpreted and interpreted static images of the DEM for M2-M4 (constant sedimentation rate models) after 4.6 Myr. (a) Uninterpreted models, sedimentary layers are coloured and assigned letters for easier discussion. Crest, flank and undeformed labels for M2 reflect the locations of thickness measurements taken to calculate thinning rates, this location is consistent across all models (M2-M6), (b) Interpreted versions of each model. Fault interpretations use displacement from initial neighbour methodology (see Figure 4, Figure S2). Interpretations highlight the width of salt withdrawal basins (deformed zones), height of diapirs, fault and fracture distributions, stratigraphic thickness variation and variable halokinetic influence vertically and laterally, discussed in the text 

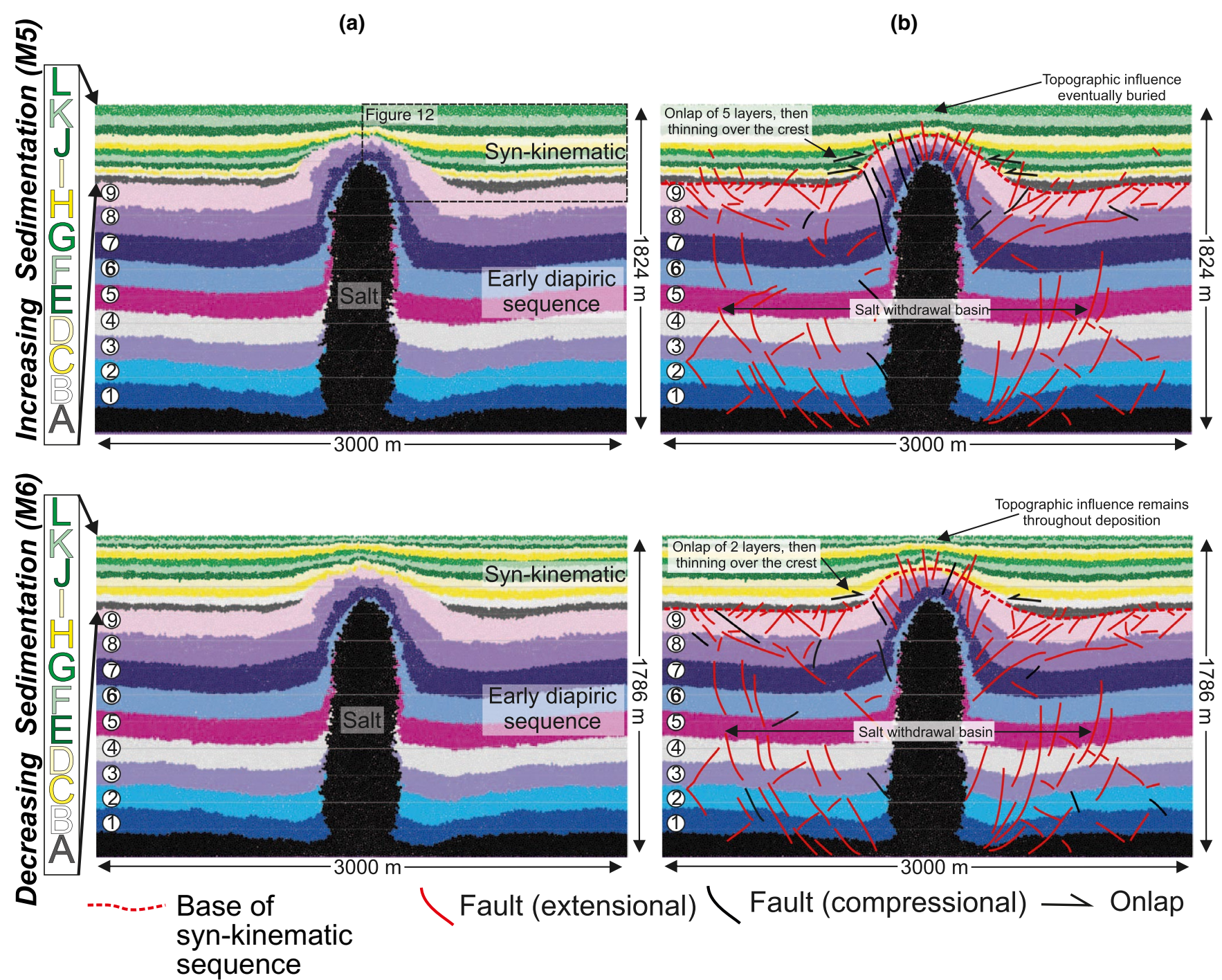

F I G U RE 6 Uninterpreted and interpreted static image of the DEM with variable sedimentation (M5 and M6) after 4.6 Myr. Displayed output represent the central 3,000 $\mathrm{m}$ of the original output model (located in Figure 3). (a) Uninterpreted models, sedimentary layers are coloured and assigned letters for easier discussion. Crest, flank and undeformed zones mentioned in the text reflect those shown in M2 (Figure 5). (b) Interpreted versions of each model. Fault interpretations use displacement from initial neighbour methodology (see Figure 4, Figure S2). Interpretations highlight the width of salt withdrawal basins (deformed zones), height of diapirs, fault and fracture distributions, stratigraphic thickness variation and variable halokinetic influence vertically and laterally discussed in the text

\section{1 | Summary of temporal relationship between halokinesis and sedimentation}

The initially horizontal basal salt layer thins adjacent to the diapir, and the diapir geometry changes from initially triangular/sinusoidal to vertically elongated during evolution (Compare $\mathrm{H}$ with $\mathrm{A}$ in Figure 3); this is consistent across all six models (Figures 3-6). Up to 45\% thinning of the salt layer, ca. $450 \mathrm{~m}$ on either side of the diapir base, occurs in all final model outputs (Figure 3h), and is accommodated by thinning in the first $2.2 \mathrm{Myr}$ of evolution, as the initial model equilibrates for diapir growth. This thinning appears not to continue throughout the model as the diapir is assumed to be fed by salt flow from out of the plane (in three dimensions), allowing diapir rise to be maintained, and preventing welding. The growth of the diapir is accompanied by withdrawal effects in the adjacent stratigraphy, which is indicated by thinning of the source layer and faulting in the basal layers (layers 1-3, Figure 3; M3 in Figure 5b). Salt withdrawal and evidence for upwards salt growth are shown by the basal part of the diapir narrowing between $T=0$ and $T=2.2 \mathrm{Myr}$ ( 0 to 22,000 time steps; A-B in Figure 3). Sediment is first introduced to all models after 2.2 Myr (22,000 timesteps; Figure 3b). Up to this time, the diapir has risen such that 'early diapiric' layers 4 and 5 are folded during its rise and thin dramatically towards the salt due to structural attenuation, assumed to be accommodated by layer-parallel slip. The early diapiric sequence, originally overlying the diapir (layers 6-9, Figure 3), 
are passively folded as the diapir rises. This results in "postdepositional' layer thickening on the flanks and thinning over the crest (Figure 3b). Above the diapir, a topographic high is generated with associated faulting in layers 6-9 observed in $T=2.2 \mathrm{Myr}$ (Figure $3 \mathrm{~b}$ ). The topographic high influences subsequent sedimentation (layers $\mathrm{A}-\mathrm{L}$ ) and is the focus of our study of stratigraphic modulation (Figure 3c-h).

Sediment is added in Stage 1 ( $\mathrm{S} 1, T=2.2 \mathrm{Myr}, 22,000$ time steps; Figure 3c), filling two salt withdrawal basins on either side of the diapir. For simplicity, following the methodology of Pichel et al. (2017), the first syn-kinematic layer, layer A, fills to a flat, standardised base level in all models, to allow consistent comparison across all models and subsequent layers are input by assigned sedimentation rate (in the case of M3, $0.3 \mathrm{~mm} / \mathrm{yr}$ ). Later in S1 ( $T=3 \mathrm{Myr}, 30,000$ time steps, Figure $3 \mathrm{~d}$ ), the rate of deposition outpaces diapir rise. Layers extend across the salt rather than onlapping it (Figure 3c,d). Throughout diapir rise, the early diapiric sequence is rotated away from the diapir crest, thickening in the adjacent depocentres, again assumed to be due to structural layer-parallel slip. The diapir stem narrows throughout evolution (compare $\mathrm{H}$ and $\mathrm{A}$, Figure 3). The thinning of early diapiric layers above the rising diapir continues into $\mathrm{S} 2$, where early diapiric layer 5 approaches vertical at the salt-sediment interface (Figure 3e,f). Upward movement of the diapir is associated with, and driven by, salt withdrawal underneath the basins, and increased displacement of faults at the base of the model (layers 1-4; Figure 3; M3 in Figure 5b).

In the final stage (S3), the early diapiric and syn-kinematic stratigraphy thin above the diapir crest, and are further rotated and thicken into the salt withdrawal basins (Figure 3g,h). Faulting is present above the diapir tip propagating through the early diapiric sequence and into the syn-kinematic sediment (M3 in Figure 5b). Throughout diapir evolution, the dip of the early diapiric layers increases towards the structure, and thus the overburden anticline steepens and narrows as sedimentation progresses (compare $\mathrm{h}$ with $\mathrm{b}$ in Figure 3). The deformation in the early diapiric overburden sequence, described here, is similar across all models (M1-M6).

The fault furthest from the diapir is taken as the edge of the halokinetically influenced part of the succession, which is ca. $1,150 \mathrm{~m}$ wide on either flank (from diapir centre to fault edge), resulting in an ca. 2,300 m zone of diapiric influence, in all models. Outside this zone, early diapiric and syn-kinematic strata appear undeformed. Salt mobility has a limited influence on sediments at the extremities of $\mathrm{M} 3$, which is consistent across all models, so in subsequent figures, only the central $3,000 \mathrm{~m}$ is shown (grey box, $T=4.6 \mathrm{Myr}$, Figure 3).

To permit comparison of stratigraphic variability across all models, subsequent figures (Figures 4-6) present all models (M1-M6) at the end of the experiment $(T=4.6 \mathrm{Myr})$. In the following section, we describe and compare diapir growth and roof folding, and stratigraphic architecture. In each case, we first present and discuss M1, the case where there is no sediment input for comparison with models in which sedimentation rate is constant (M2-M4), increasing (M5) and decreasing (M6).

\section{2 | Diapir growth and roof folding}

\subsection{1 | Diapir rise with no sedimentation (M1)}

In $\mathrm{M} 1$, the diapir crest rises a total of $425 \mathrm{~m}$, and the final width of the early diapiric folded roof, taken from the greatest change in dip in layer 9 is $961 \mathrm{~m}$ (Figure 4; Figure S1). These values represent the base-case to compare the effect of different sedimentation rates on the final geometry of the salt structure and the early diapiric and syn-kinematic stratigraphic architectures (Tables 2 and 3; Figures 5 and 6).

\subsection{2 | Constant sedimentation rates (M2-M4)}

Under slow (M2), intermediate (M3) and fast (M4) constant sedimentation rates the diapir rises by 393, 363 and $297 \mathrm{~m}$, respectively (Figure 5). Diapir growth compared to M1 is reduced by $8 \%, 15 \%$ and $30 \%$ for the different aggradation cases, respectively (Table 2). The width of the early diapiric folded roof decreases from $961 \mathrm{~m}$ in M1 to $770 \mathrm{~m}$ (M2), $760 \mathrm{~m}$ (M3) and $734 \mathrm{~m}$ (M4), which accounts for a 20\%-24\% reduction relative to $\mathrm{M} 1$. Where syn-kinematic stratigraphy is present across the model (i.e. not in M2), the syn-kinematic folded roof is measured from the point within layer $\mathrm{F}$ where there is the greatest change in dip (Figure S1). Layer F is chosen as it is the first layer that is laterally extensive across all models (M3-M6). The syn-kinematic folded roof is 839 and $890 \mathrm{~m}$ wide in M3 and M4, respectively. The syn-kinematic roofs are therefore $110 \%$ and $120 \%$ greater than the width of the early diapiric folded roof in the same models (Figure S1).

\subsection{3 | Variable sedimentation rates: Increasing (M5) and decreasing (M6) sedimentation rates}

In M5, under increasing sedimentation rate, the diapir rises by $368 \mathrm{~m}$, a decrease of $14 \%$ compared to M1. Under decreasing sedimentation rate conditions (M6), the diapir rises by $346 \mathrm{~m}$, a $19 \%$ reduction when compared to the base case M1 (Table 2; Figures 6 and 7). The early diapiric folded roof width is reduced to ca. $750 \mathrm{~m}$ in both models, a decrease of $22 \%$ compared to M1 (Table 2; Figure 7). The syn-kinematic folded roof is 723 and $872 \mathrm{~m}$ in M5 and M6, respectively, representing a $4 \%$ reduction and $16 \%$ increase compared to the early diapiric folded roof in the same model. 


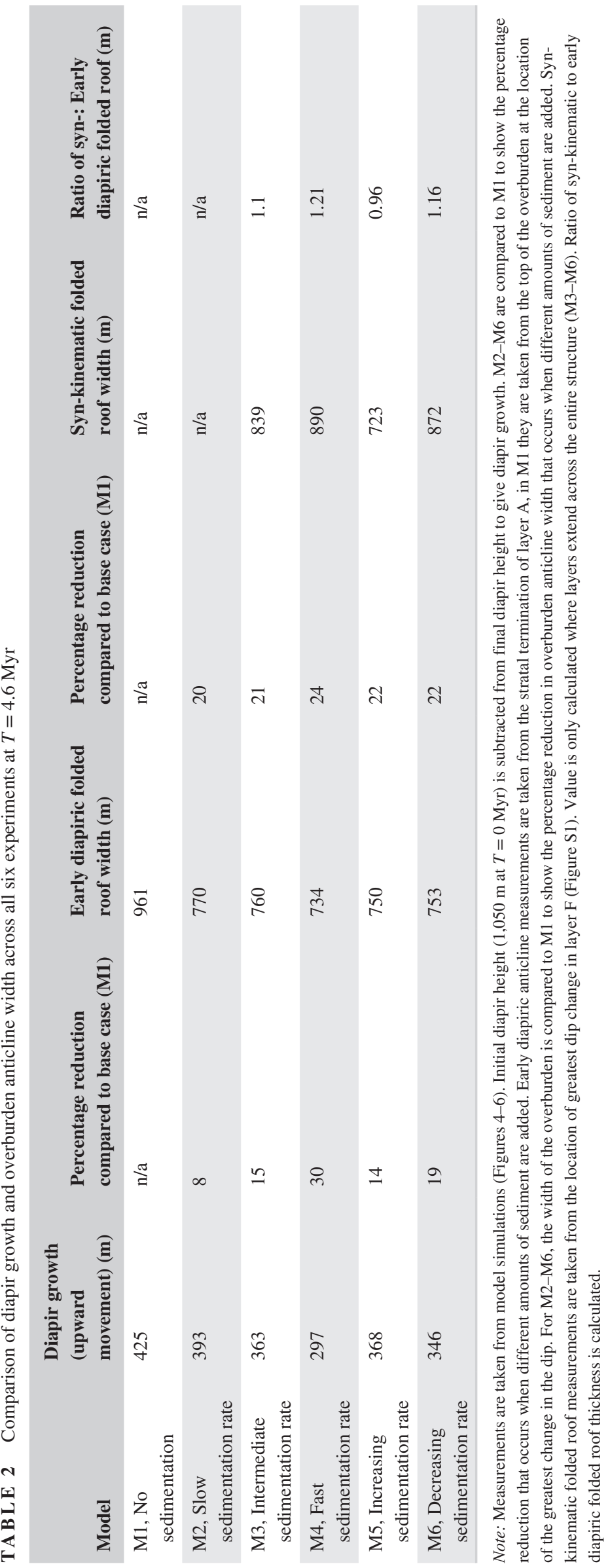




\section{3 | Effect of sedimentation rate on stratigraphic architecture}

Here, we discuss the lateral extent, thinning rates, and termination styles of stratigraphy onto the topographic high for M2-M6. In all models, layer A fills to a fixed base level and therefore does not represent the sedimentation rate of S1, so the first layer described is layer B. Across all models, layer A heals the topography. This step reduces irregularities with the upper surface of layer 9 that might influence syn-kinematic sedimentation. This partial healing of topography, which is comparable to hemipelagic deposition prior to the activation of a depositional system, allows for direct comparison across all models (Cumberpatch, Finch, et al., 2021; Pichel
TA B L E 3 Comparison of stratigraphic thinning across M2-M6

\begin{tabular}{|c|c|c|c|c|c|c|c|}
\hline Model & $\begin{array}{l}\text { U-C } \\
(\%)\end{array}$ & $\begin{array}{l}\text { U-C } \\
(\% / \mathrm{m})\end{array}$ & $\begin{array}{l}\text { U-F } \\
(\%)\end{array}$ & $\begin{array}{l}\text { U-F } \\
(\% / \mathrm{m})\end{array}$ & $\begin{array}{l}\text { F-C } \\
(\%)\end{array}$ & $\begin{array}{l}\text { F-C } \\
(\% / \mathrm{m})\end{array}$ & $\begin{array}{l}\text { U- } \\
\text { F:F-C }\end{array}$ \\
\hline Slow (M2) & - & - & 34.4 & 0.029 & - & - & - \\
\hline $\begin{array}{l}\text { Intermediate } \\
\text { (M3) }\end{array}$ & 54.5 & 0.037 & 19.2 & 0.017 & 35.3 & 0.1 & $1: 6.1$ \\
\hline $\begin{array}{l}\text { Layers } B \text { and } C \\
{[\sim \mathrm{S} 1]}\end{array}$ & - & - & 26.4 & 0.023 & - & - & - \\
\hline $\begin{array}{l}\text { Layers D-H } \\
{[\sim \mathrm{S} 2]}\end{array}$ & 60.1 & 0.040 & 14.5 & 0.011 & 45.6 & 0.13 & $1: 10.3$ \\
\hline Layers I-L [S3] & 23.2 & 0.015 & 6.3 & 0.005 & 16.9 & 0.048 & $1: 8.8$ \\
\hline Fast (M4) & 32.5 & 0.022 & 11.6 & 0.010 & 20.9 & 0.060 & $1: 5.9$ \\
\hline $\begin{array}{l}\text { Layer B [Early } \\
\text { S1] }\end{array}$ & - & - & 47.0 & 0.041 & - & - & - \\
\hline $\begin{array}{l}\text { Layers C \& D } \\
\text { [Late S1] }\end{array}$ & 38.4 & 0.026 & 12.9 & 0.011 & 25.5 & 0.073 & $1: 6.5$ \\
\hline $\begin{array}{l}\text { Layers E-H } \\
{[\mathrm{S} 2]}\end{array}$ & 29.7 & 0.019 & 8.6 & 0.007 & 21.1 & 0.06 & $1: 8$ \\
\hline Layers I-L [S3] & 2.35 & 0.0016 & 1.04 & 0.0009 & 1.3 & 0.037 & $1: 4.1$ \\
\hline $\begin{array}{l}\text { Increasing } \\
\text { (M5) }\end{array}$ & 58.3 & 0.039 & 19.3 & 0.017 & 38.9 & 0.11 & $1: 6.6$ \\
\hline $\begin{array}{l}\text { Layers B-D } \\
\text { [S1] }\end{array}$ & - & - & 61.1 & 0.053 & - & - & - \\
\hline $\begin{array}{l}\text { Layer E [Early } \\
\text { S2] }\end{array}$ & - & - & 24.8 & 0.0022 & - & - & - \\
\hline $\begin{array}{c}\text { Layers F-H } \\
\text { [Late S2] }\end{array}$ & 60.6 & 0.040 & 15.9 & 0.014 & 44.8 & 0.128 & $1: 9.2$ \\
\hline Layers I-L [S3] & 21.5 & 0.014 & 6.7 & 0.006 & 14.7 & 0.042 & $1: 7.2$ \\
\hline $\begin{array}{l}\text { Decreasing } \\
\text { (M6) }\end{array}$ & 52.4 & 0.035 & 18.6 & 0.016 & 33.9 & 0.097 & $1: 5.9$ \\
\hline $\begin{array}{l}\text { Layer B [Early } \\
\text { S1] }\end{array}$ & - & - & 37.4 & 0.017 & - & - & - \\
\hline $\begin{array}{l}\text { Layers C and D } \\
\text { [Late S1] }\end{array}$ & 39.6 & 0.026 & 10.3 & 0.009 & 29.3 & 0.084 & $1: 9.3$ \\
\hline $\begin{array}{l}\text { Layers E-H } \\
{[\mathrm{S} 2]}\end{array}$ & 42.3 & 0.028 & 11.4 & 0.009 & 30.8 & 0.088 & $1: 8.8$ \\
\hline Layers I-L [S3] & 43.9 & 0.029 & 19.5 & 0.017 & 24.5 & 0.069 & $1: 4.1$ \\
\hline
\end{tabular}

Note: Bold headings indicate each model and show the total thinning for all stratigraphy, beneath each heading this is divided by sedimentary package. Layer A is excluded as it fills to the base level in all models. Layers are subdivided based on observational differences (e.g. lateral extent across the model) and are broadly grouped into their sedimentation stage (S1, S2, S3). Percentage thinning and normalised thinning rates $(\% / \mathrm{m})$ are shown for U-C (Undeformed to Crest, i.e. the total model), U-F (Undeformed to Salt Flank) and F-C (Salt Flank to Crest). In layers that do not extend across the entire model no results exist for U-C and F-C. The final column displays the ratio of the normalised thinning rate between the Undeformed to Salt Flank and the Salt Flank to Crest sections, to show how much more thinning is observed adjacent to the diapir. Locations of undeformed, flank and crest measurements are shown in Figure 5, and are the same for all models to ensure direct comparison. 
et al., 2017, 2019) although it reduces the effect of thinning and folding of subsequent layers (B-L). Stratigraphic architecture and thinning rates (Table 3 ) are discussed with reference to three points that remain fixed throughout all models: the crest, flank and undeformed zone (see uninterpreted M2 in Figure 5).

\subsection{1 | Constant sedimentation rates (M2-M4)}

Syn-kinematic layers (B-L) are not laterally extensive in M2; this model is defined by slow sedimentation rates. In this case, deposition is restricted to primary salt withdrawal basins, with no sedimentation occurring over the crest of the early diapiric anticline. All layers terminate adjacent to the diapir, with the uppermost layers (I-L) onlapping the remnant topography created by the layers below (Figure 5). The entire stratigraphic package thins by $34 \%$, at a rate of $0.029 \% / \mathrm{m}$ from the undeformed zone to salt flank, before pinching-out towards the crest.

In M3, the model defined by intermediate sedimentation rates, the earliest syn-kinematic strata (layers B and C) are preserved only in the salt withdrawal basin, offset some distance from the diapir (Table 3). However, in contrast to M2, layers D-L are laterally extensive across the model, extending across the diapir crest (Table 3 ). The overall stratigraphic thinning for intermediate aggradation is 55\% from undeformed zone to crest, at a rate of $0.037 \% / \mathrm{m}$, with over one-third of this occurring between the undeformed zone and flank, accounting for $19 \%$ thinning at a rate of $0.017 \% / \mathrm{m}$. Thinning rates of $0.1 \% / \mathrm{m}$, totalling $35 \%$ stratigraphic thinning (almost two-thirds of the overall thinning observed across M3) are observed from flank to crest. The thinning rate between the salt flank and the crest is 6.1 times greater than that between the undeformed section and the flank (Table 3).

In the fast sedimentation model, M4, all layers are extensive across the model except for layer B (Figure 5; Table 3). The overall stratigraphic thinning for fast aggradation is $33 \%$ from the undeformed section to crest at a rate of $0.022 \% / \mathrm{m}$. Over one-third of this total thinning is between the undeformed section and the salt flank, accounting for $12 \%$ stratigraphic thinning at a rate of $0.01 \% / \mathrm{m}$, and the other almost two-thirds occur between the salt flank and the crest with a thinning rate of $0.06 \%$ accounting for $21 \%$ stratigraphic thinning. The thinning rate between the salt flank and the crest is 5.9 times greater than that between the undeformed section and the flank (Table 3).

\subsection{2 | Variable sedimentation rates: Increasing} (M5) and decreasing (M6) sedimentation rates

In M5 (increasing sedimentation rate), layers B-D represent slow sedimentation; these layers are restricted to the salt withdrawal basin on either side of the structure and thintowards the salt-influenced topography before pinching out. Layers $\mathrm{E}-\mathrm{H}$ were deposited under intermediate sedimentation rates. Layer $\mathrm{E}$ does not extend across the model and thins towards the topography between the undeformed section and the salt flank, before pinching out towards the crest. Layers $\mathrm{F}-\mathrm{H}$ are extensive across the model. Layers I-L were deposited under the fast sedimentation rate, and are laterally extensive across the entire model (Figure 6; Table 3). Overall thinning in the increasing sedimentation model accounts for $58 \%$ of total stratigraphic thinning at an average rate of $0.039 \% / \mathrm{m}$; two-thirds of this thinning takes place between the salt flank and the crest, accounting for 39\% stratigraphic thinning at a rate of $0.11 \% / \mathrm{m}$. The remaining third of the thinning occurs between the undeformed section and the salt flank, at a rate of $0.017 \% / \mathrm{m}$ accounting for $19 \%$ stratigraphic thinning. The thinning rate between the salt flank and the crest is 6.6 times greater than that between the undeformed section and the salt flank (Table 3).

In M6 (decreasing sedimentation rate), layers B-D represent fast sedimentation. Layer B is isolated to either side of the diapir and thins between the undeformed section and the flank before terminating towards the diapir (Table 3). Layers $\mathrm{C}$ and $\mathrm{D}$ are laterally extensive. Layers $\mathrm{E}-\mathrm{H}$ represent intermediate sedimentation and are deposited across the entire model. Layers I-L are deposited under slow sedimentation and are extensive across the whole model, but thin markedly over the crest (Figure 6; Table 3). The overall stratigraphic thinning for the decreasing sedimentation rate model is $52 \%$ at a rate of $0.035 \% / \mathrm{m}$. Just over one-third of this thinning takes place between the undeformed section and the diapir flank, accounting for $19 \%$ stratigraphic thinning at a rate of $0.016 \% / \mathrm{m}$, and the remaining two-thirds of thinning occurs between the flank and the crest, at a rate of $0.097 \% / \mathrm{m}$, accounting for $34 \%$ stratigraphic thinning. The thinning rate between the salt flank and the crest is 5.9 times greater than that between the undeformed section and the salt flank (Table 3).

\section{4 | SUMMARY OF HALOKINETIC INFLUENCE}

\section{1 | Diapir growth and roof folding}

In our model, we invoke a constant upward movement, or growth, of the salt diapir. Therefore, our models show how different sedimentation rates can dampen the late-stage growth of diapirs. The greatest upward movement of the diapir is observed in the model with no sedimentation (M1) (Table 2; Figure 7), because in this case there is no roof to resist the upward flux of salt. M1 is taken as the base case. Upward movement (growth) of the diapir is reduced with the addition of sediment (Table 2; Figures 5 and 6), which in essence 


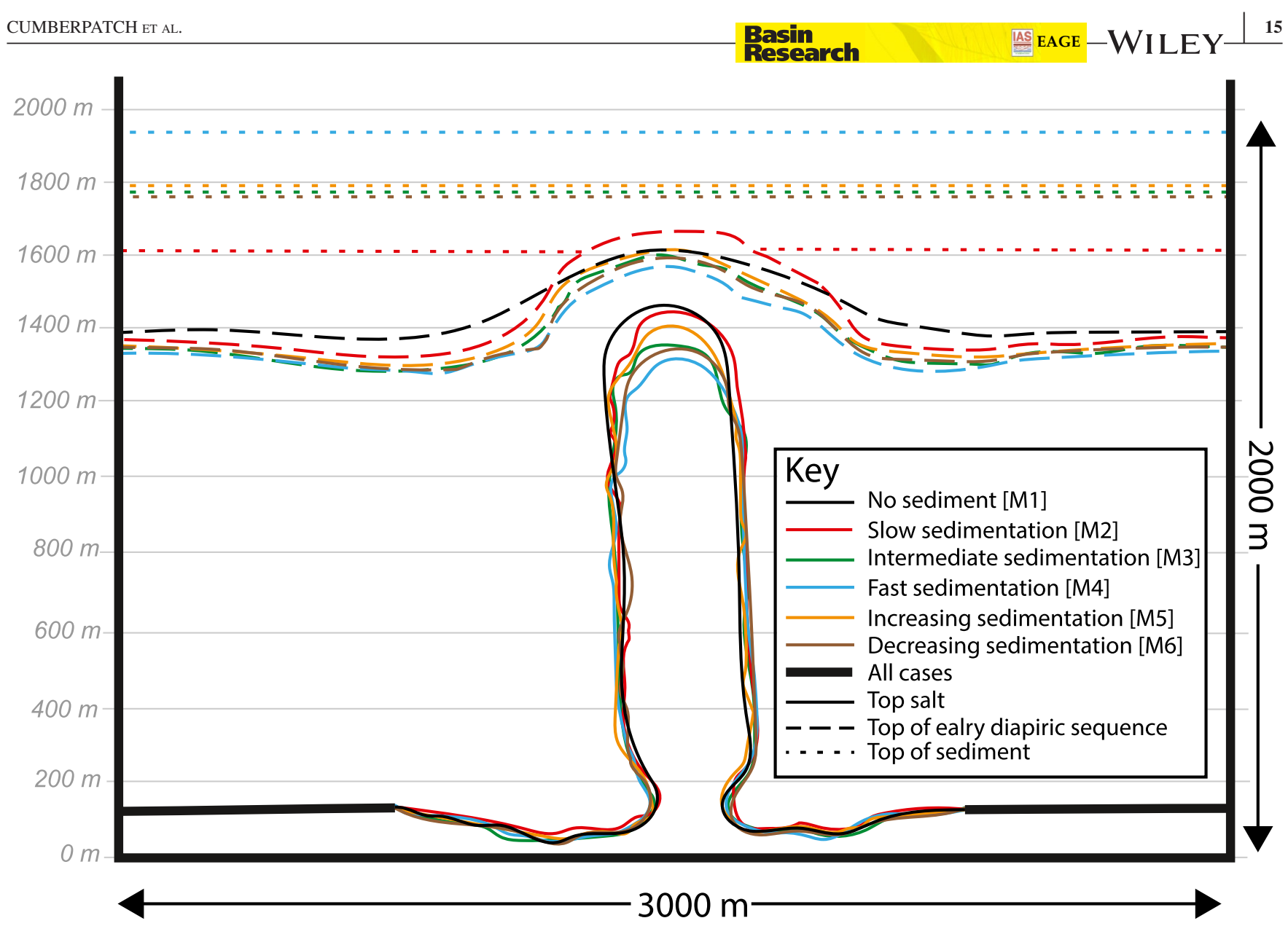

F I G U RE 7 Diagrammatic comparison of static 4.6 Myr DEM across all models. Comparison between top salt (solid line), top of the overburden (dashed line) and top of the sediment (dotted line). The top of sediment is not shown in M1 as none is added. All cases have a similar top salt outside the deformed zone (shown by a bold black line). Diapir growth and width of the early diapiric overburden anticline are reduced in M2-M6 when compared to M1 due to overpressure caused by sedimentation (see Table 2). Grey lines indicate 200 m divisions vertically. Located in Figure 3

increases the roof thickness towards the limit where diapir growth can occur (i.e. diapir height approaches $<66 \%$ of overburden: Schultz-Ela et al., 1993). The amount of growth decreases, compared to the base case (M1), with increasing sedimentation rate (being limited to $70 \%$ in M4), showing that sedimentation rate is a key control on the burial of salt topography. This observation is in agreement with existing models (Fuchs et al., 2011; Giles \& Lawton, 2002; Hudec \& Jackson, 2007; Jackson \& Hudec, 2017; Peel et al., 2020).

We also note that the anticline defining the early diapiric folded roof is widest in M1 and decreases with an increasing sedimentation rate (Table 2; Figures 7 and 9). In models with added sedimentation (M2-M6), the early diapiric roof anticline is 20\%-24\% narrower than in M1 (no sedimentation). The lack of variability between different sedimentation conditions may imply that sedimentation rate has only a minor control on early diapiric anticline width, with other controls such as salt supply, salt viscosity and regional tectonics (not modelled) being more important (Fuchs et al., 2011; Koyi, 1998). However, the anticline within the syn-kinematic folded roof is widest in M4, appearing to widen with increasing stratigraphic thickness (i.e. sedimentation rate). Synkinematic folded roof thicknesses are more variable across the models, because they are controlled by the sedimentation rate. Increasing the syn-kinematic folded roof width with sedimentation rate supports fold wavelengths being larger for thicker overburdens (Bonini, 2003; Davison, et al., 2000; Duffy et al., 2018; Hudec \& Jackson, 2011).

\subsection{Fault distribution and deformation zone extent}

Fault distribution and salt withdrawal basin extent are interpreted using the nearest neighbour outputs (Figure 4; Figure S2). Nearest neighbour outputs highlight the amount of displacement that has occurred during 4.6 Myr, relative to an element's initial neighbours; this is used to highlight discontinuities as a proxy for faults. Fault distributions are broadly similar across all models (Figures 4-6) and are summarised 


\section{Flank stratigraphy comparison}
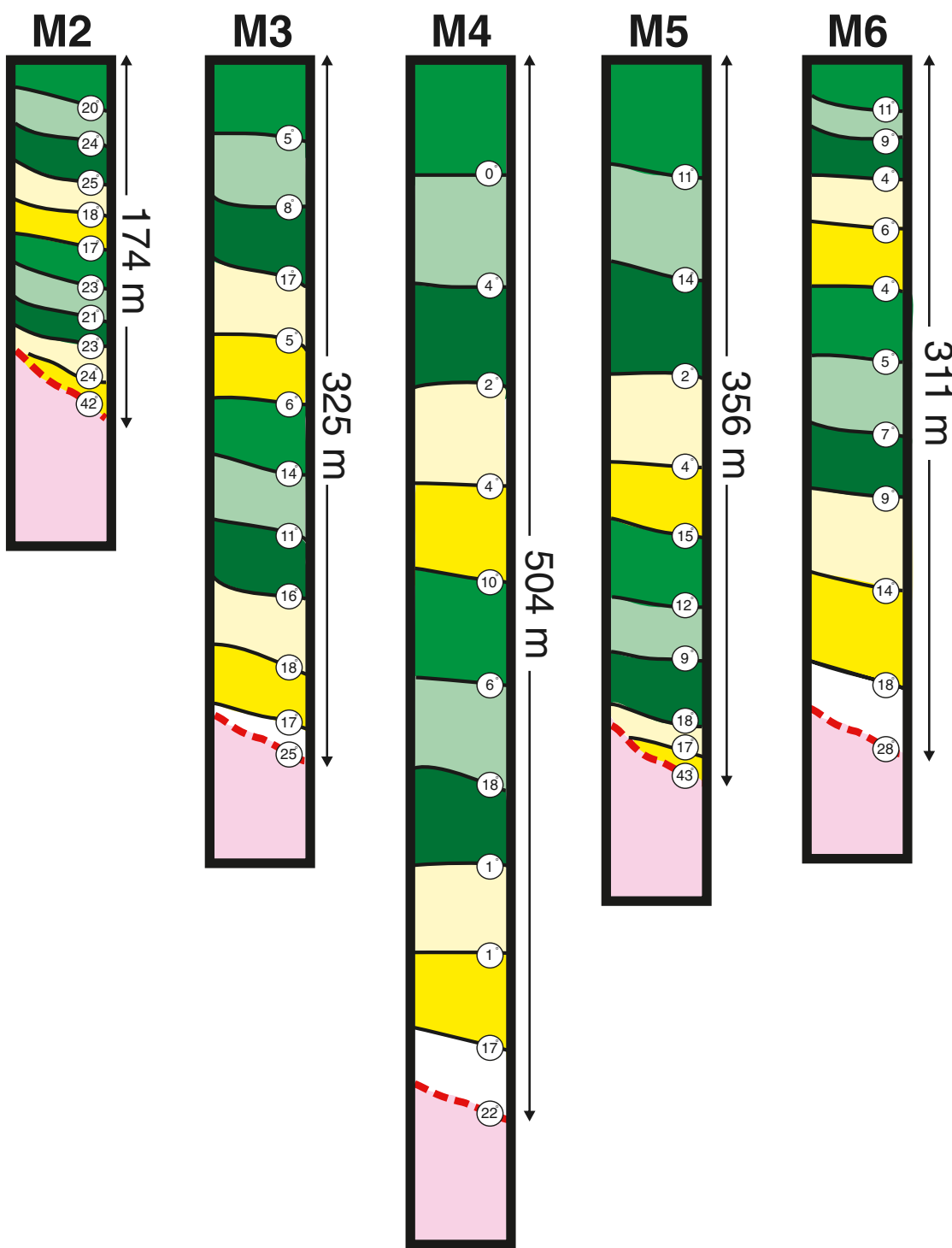
Syn-kinematic
layers

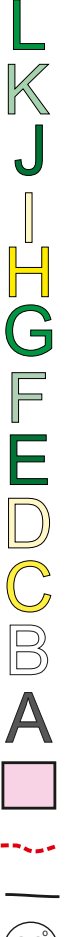

Not present in the flank locations in any models

Early diapiric sequence

base of syn-kinematic sequence

Bedding

(20) Bedding dip

F I G URE 8 Comparison of the flank section stratigraphy across all models with sediment (M2-M6). See Figure 5 for the location of the flank profile, which is the same across all models. Thicknesses and bedding orientation highlighted. The flank location shows the most deformation in all models, greatest modulation is observed in M2, and least modulation is observed in M4. Generally, modulation decreases upwards, however, in M6 bed dip increases in layers $\mathrm{K}$ and L. Models give an indication of the sedimentary thickness and bed rotation expected adjacent to salt diapirs under different sedimentation rates, aiding the prediction of sediment thickness and bed rotation in the subsurface salt sediment interface

here. Numerous predominantly extensional faults, with variable dip directions, are identified in the early diapiric sequence in all experiments. These faults have displacements of metres to 100 s of metres, with the greatest throws being observed between layers 1-7 (Figures 4-6). More contractional structures are observed in M4 and M6 compared to the other models. This corresponds with diapirs experiencing the greatest reduction in growth (Figures 5 and 6; Table 2), and could suggest that localised compressional stresses increase as the diapir is restrained beneath early thick sedimentation due to overpressure (Jackson \& Hudec, 2017). However, this could also be an artefact of subtle differences in early diapiric and syn-kinematic anticlines and variations in salt topography. Steep structures appear to develop over the crest of the growing diapir, but are difficult to decipher in terms of slip style (i.e. normal or reverse) due to the relatively small number of displaced neighbouring elements. These crestal structures extend into the syn-kinematic strata 
(layers A-J) overlying the overburden anticline (M3-M6); these discontinuities are largest and extend furthest into the syn-kinematic overburden under greater sedimentation rates (compare M4 with M3; Figure 5). In all experiments, layers 8 and 9 are dominated by small-scale faults that are localised to those layers.

The edge of the salt withdrawal basin is taken as the distance of the furthest faults from the diapir; outside this zone, the strata are undeformed (Figures 4-6). The salt withdrawal basin, and associated deformation zone, is ca. 2,300 m wide in all models, accounting for three times the initial maximum width of the diapir (Figures 4-6). The similar extent of the salt withdrawal basin across all experiments suggests that syn-kinematic sedimentation only has a minor control on the deformation of early diapiric layers and structural configuration.

\section{3 | Stratigraphic architecture variability with sedimentation rate}

Here, the variability in thinning rate is compared between different models with syn-kinematic sedimentation. Layer A is excluded from descriptions in all models, and thus from our comparisons, as it fills to a linear, instantaneous base level and therefore does not always represent the sedimentation rate of S1. In the absence of layer A, more layers would onlap and less would be laterally extensive across the models as more relief would need to be healed. However, the inclusion of a consistently thick layer A across all models enables easier comparison and could represents a pelagic drape that partially heals topography prior to the onset of a coarser-grained depositional system (e.g. a turbidity current-fed channel and/ or lobe). Therefore, 11 layers (B-L) are described and compared in Table 3.

Under slow sedimentation rate (M2) all 11 layers of onlap topography and are not laterally extensive. Under intermediate sedimentation rate (M3) two layers onlap and nine are laterally extensive. In fast sedimentation (M4) and decreasing sedimentation (M6) this rises to 10 laterally extensive layers and one onlapping layer. Under increasing sedimentation rate (M5), the initial four layers (including three which are deposited under slow sedimentation) onlap topography and the remaining 7 are laterally extensive (Figure 5). As expected, layers are more laterally extensive under higher sedimentation, suggesting that the effects of halokinetic modulation decrease more rapidly upwards under higher sedimentation rates (Cumberpatch, Finch, et al., 2021; Peel, 2014; Sylvester et al., 2015). The final stratigraphic thickness is greatest under fast sedimentation rate (M4, $570 \mathrm{~m})$, least under slow sedimentation rate (M2, $228 \mathrm{~m})$, and at a similar intermediate level for intermediate (M3, $401 \mathrm{~m}$ ), increasing (M5, $441 \mathrm{~m}$ ) and decreasing
(M6, $382 \mathrm{~m}$ ) sedimentation rates, logically showing that net sediment volume is the most important control on sediment thickness (Figures 7-9).

Overall stratigraphic thinning, from the undeformed zone to the flank, is greatest under slow sedimentation rate (M2, $34 \%$ thinning) and least under fast sedimentation rate (M4, $12 \%$ thinning) (Table 3). This shows that stratigraphic thinning rates decrease with increasing sedimentation, suggesting that diapir modulation (thickness and dip variability) decreases quicker under higher sedimentation rate (Fuchs et al., 2011; Koyi, 1998; Pratson \& Ryan, 1994).

In almost all of the models, the thinning rate is between 5.9 and 6.1 times greater between the salt flank and the crest than it is between the undeformed section and the salt flank (Table 3; Figure 9). This rate is higher (6.6 times) under increasing sedimentation (M5), which suggests that salt structures have greater influence in models where sedimentation rate is initially slow (e.g. S1 in M5; Fuchs et al., 2011; Giles \& Lawton, 2002; Giles \& Rowan, 2012; Jackson \& Hudec, 2017).

Whilst the primary mechanism modulating the stratigraphic architecture is stratigraphic thinning, stratigraphic thickening into basins driven by salt withdrawal at depth must not be disregarded. Localised thickening into salt withdrawal basins is observed in all models. Such thickening accounts for $13 \%$ of the stratigraphic thickening in M5 (Cumberpatch, Finch, et al., 2021). This highlights how the presence of a growing diapir can be associated with localised additional accommodation (as well as a reduction of accommodation) due to the at-depth evacuation of salt from the source layer to feed the growing diapir, as is evidenced by subtle thickening into the basin (Figures 5 and 6). Accommodation reduction over the crest of the diapir is driven by diapir growth, which is recorded by stratigraphic thinning. Accommodation increases in salt withdrawal basins are accounted for by stratigraphic thickening and salt migration at depth.

Through time, thickening and thinning are eventually reduced as the halokinetic modulation on stratigraphy is minimised with the burial of the salt-cored topographic high and its flanking depocentres. In all experiments with layers that extend across the entire model, the thinning rate and bedding orientation change up-section (Table 3, Figure 8). In M2-M5, a decrease in thinning rate up-section is observed. Bedding orientations are variable but generally decrease (flatten) upwards in M2-M5. However, under decreasing sedimentation (M6) an overall increase in thinning rate upsection is noted (Figure 6; Table 3), in addition to a slight increase in bedding dip between layers J, $\mathrm{K}$ and $\mathrm{L}$. This suggests that initially thicker layers are less deformed, but that as diapir growth continues and sedimentation decreases, thin layers are still influenced by topography associated with rising salt (Giles \& Lawton, 2002; Giles \& Rowan, 2012; 
Hudec \& Jackson, 2007; Soutter et al., 2019; Sylvester et al., 2015). Overall, halokinetic modification reduces with increasing sedimentation rate as halokinetic bathymetry is buried. Typically, such alteration decreases up stratigraphy, and laterally outwards from the diapir in agreement with outcrop and subsurface analogues globally (Figures 9-11; e.g. Banham \& Mountney, 2013a, 2013b, 2014; Cumberpatch, Kane, et al., 2021; Doughty-Jones et al., 2017; Giles \& Lawton, 2002; Giles \& Rowan, 2012; Kernen et al., 2012, 2020; Mayall et al., 2010; Oluboyo et al., 2014; Poprawski et al., 2014, 2016; Pratson \& Ryan, 1994; Ribes et al., 2015; Rodriguez et al., 2020; Wu et al., 2020).

\section{5 | DISCUSSION}

\section{1 | Comparison to natural examples}

A key challenge for numerical models is ground-truthing against natural prototypes (Burgess, 2012; Oreskes et al., 1994). Here, the key findings and predictions from the DEM (Figure 9) are compared to published subsurface (Figures 10 and 11) and field analogues (Figure 12) to understand their applicability and limitations.

\subsection{1 | Comparison to subsurface: Stratigraphy} around the Pierce diapirs, Eastern Central Graben, UK North Sea

Jurassic-Pleistocene syn-kinematic stratigraphy around the north and south Pierce diapirs, Eastern Central Graben, UK North Sea (Figure 10) shows evidence for halokinetically driven changes in bed thickness and dip (Figures 10e and 11c; Birch \& Haynes, 2003). Pierce's tectonostratigraphic history spans ca. $200 \mathrm{Myr}$ and is summarised as Jurassic reactive-active diapirism, followed by Cretaceous-Cenozoic passive diapirism, and contraction-driven active diapirism during Alpine compression (Scott et al., 2010). Despite a longer-lived and more complex evolution, the Pierce diapirs show geometrical similarities with several of our DEMs (Figures 9 and 10). In the Pierce example, stratigraphy is near horizontal ca. $2 \mathrm{~km}$ away from both diapirs, but is upturned adjacent to them, comparable with model results (Figures 5, 6,9 , and 10). An average seismic velocity of $2,000 \mathrm{~m} / \mathrm{s}$ was used for approximate depth conversion for the entire time-migrated seismic data to calculate the thinning rate for stratigraphy adjacent to the Pierce field. This is an oversimplification of seismic velocity, which varies with depth and lithology. However, it is suitable to give a broad comparison to our modelled values (Table S2). The generation of brittle deformation throughout the Cenozoic stratigraphy over the crest of both north and south Pierce (Figure 11; Carruthers et al., 2013) corresponds to high zones of relative displacement across the crest of the diapir, in M3-M6, which extend into the syn-kinematic stratigraphy (Figures 5 and 6, Figure S1). Similar crestal deformation has been demonstrated in physical models (e.g. Davison et al., 1993). Different model outputs may be applicable to different parts of stratigraphy due to the changing ratio of diapir rise rate and sedimentation rate. For example, stratigraphic architectures comparable to M2, M3 and M5 are observed in different stratigraphic packages around the Pierce diapirs (Figure 11).

The unique observation from M2 (slow sedimentation) is non-extensive layers that thin towards and eventually onlap and pinch out against the long-lived, salt-related topographic high (Figure 9a). M2 results are analogous to the Top Cretaceous (lime green) to Mid Eocene (red) stratigraphy around the Pierce diapirs (Figure 11c), which is not laterally extensive across the diapirs (Birch \& Haynes, 2003; Carruthers et al., 2013; Davison, Alsop, Birch, et al., 2000; Scott et al., 2010). The Top Cretaceous - Mid Eocene package, equivalent to $\mathrm{S} 1-\mathrm{S} 3$ in the models, thins significantly towards both diapirs, before onlapping the flanks (Figures 9a and 10a,c). The amount and rate of thinning reduce through time, from $51 \%$ at $0.044 \% / \mathrm{m}$ in the Paleocene (Top Cretaceous - Top Lista interpretations) to $21.3 \%$ at $0.019 \% / \mathrm{m}$ between in the Eocene (Tay and Eocene interpretations (Table S2)) in agreement with model observations showing thinning rates reducing upwards. These values are similar to the overall thinning of the slow sedimentation model (34\%, at $0.029 \% / \mathrm{m}$; Table 3). Despite this apparent similarity in thinning rate values, regional sediment volumes are high throughout the Palaeocene $\left(10,000 \mathrm{~km}^{3} / \mathrm{my}\right.$; Liu \& Galloway, 1997). Specific lithostratigraphic units such as the Forties Sandstone are associated with ca. $200 \mathrm{~m}$ of sandstone deposited in ca. 1 million years (Eldrett et al., 2015; Kilhams et al., 2014). Sedimentation rates for the UK Palaeocene stratigraphy are uncertain, and spatially and temporarily variable around the Pierce diapirs, with rates ranging from 0.085 to $0.4 \mathrm{~mm} / \mathrm{yr}$ (Eldrett et al., 2015; Kilhams et al., 2014; Liu \& Galloway, 1997). The lower values are in broad agreement with our slow sedimentation input values. The upper end, however, indicates intermediate - fast sedimentation rates in our models, which have probably been coeval with very high diapir rise rates to form an overall geometry typical of slow sedimentation rates (Carruthers et al., 2013). This is further evidenced by the steep upturning of stratigraphy adjacent to the diapirs (Figure 11c; Giles \& Lawton, 2002; Hudec \& Jackson, 2007). In our model, we isolate and vary sedimentation rate, whilst in reality the dynamic ratio of sedimentation rate and diapir rise rate control stratigraphic architecture. It is suggested that during the Paleocene - Eocene sedimentation rates were high, but diapir rise rates were higher, likely driven by sediment loading (Carruthers et al., 2013) creating a relative effect of a 'low sedimentation rate' akin to our M2. 
(A) Slow Sedimentation (M2)

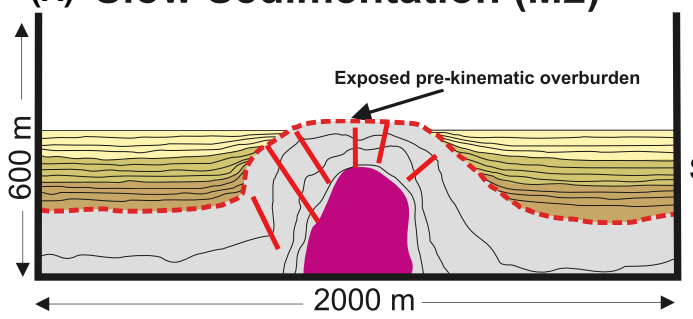

Syn-kinematic

Early diapiric

sequence
- Non-extensive layers

- Diapir forms topographic high

- Thinning towards the diapir

- Onlap onto the overburden

- Wide overburden anticline

- Long-lived salt influence

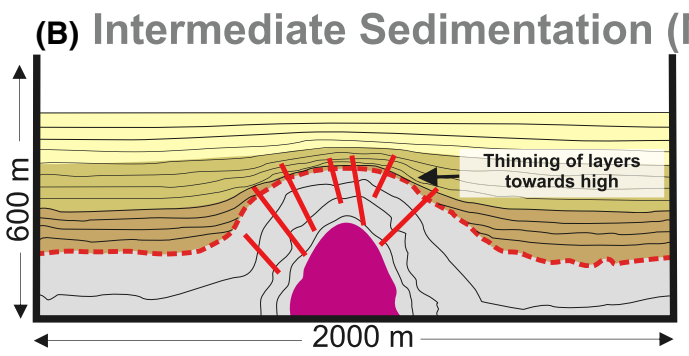

(M3)

(C) Fast Sedimentation (M4)

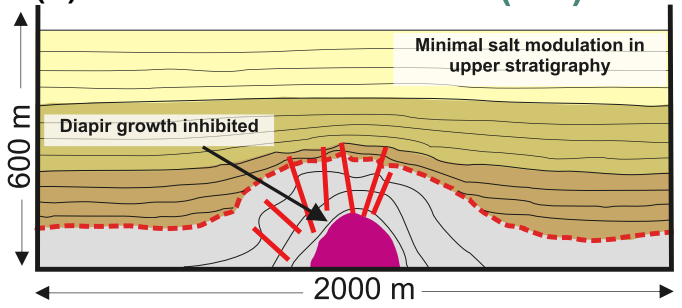

Early diapiric sequence
Early diapiric

sequence
- Initially non-extensive layers

- Early overburden onlap

- Layers thin towards diapir

Syn-kinematic

- Percentage thinning decreases upwards

- Halokinetic influence decreases upwards

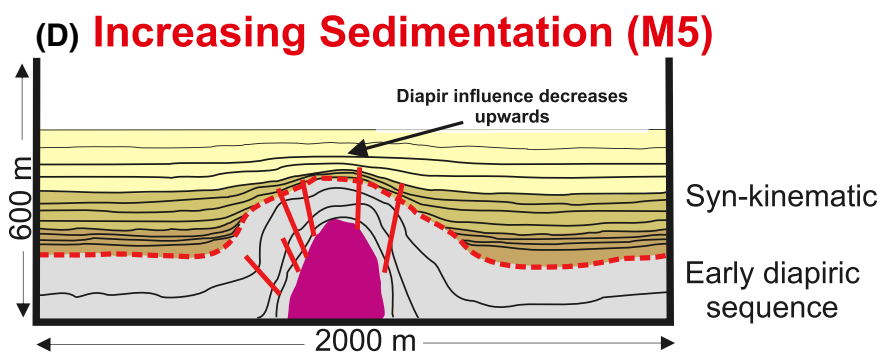

- Laterally extensive layers

- Diapir quickly buried

- Initial onlap, then thinning

Syn-kinematic - Halokinetic influence decreases upwards

- Narrow overburden anticline

- Reduced salt growth

- Sedimentation rate rises to simulate progradation

- Initially non-extensive onlapping layers

- Then thinning of layers

- Halokinetic influence decreases upwards

- Top layer not deformed

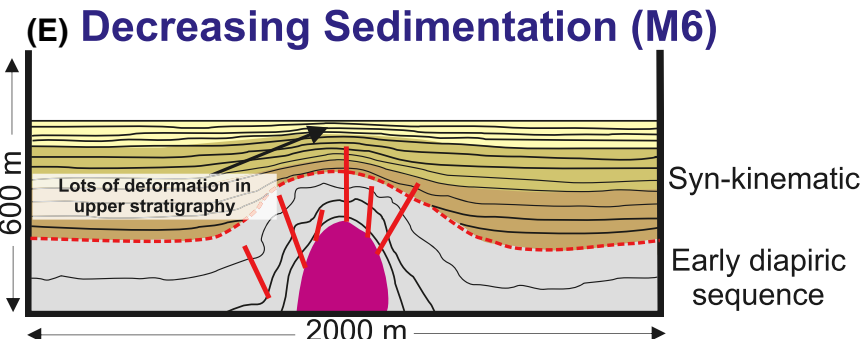

- Sedimentation rate decreases to simulate retrogradation

- First layer non-extensive

- Thinning rate increases upwards

- Halokinetic influence increases upwards

- Top layers thin rapidly towards high
Base of syn-kinematic sequence Fault
Salt
Overburden
Stage $1^{*}(\mathrm{~S} 1,2.2-3 \mathrm{Myr}) \square$ Stage $2^{*}(\mathrm{~S} 2,3-3.8 \mathrm{Myr})$
Stage $3^{*}(\mathrm{~S} 3,3.8-4.6 \mathrm{Myr})$

F I G U RE 9 Schematic interpretations of M2-M6, focussed on the central 2,000 m of the syn-kinematic stratigraphy, located in Figure 3. Bullet points highlight the key observations specific to each modelled scenario. Crestal faults are simplified from Figures 4-6 to better visualise syn-kinematic stratigraphy 


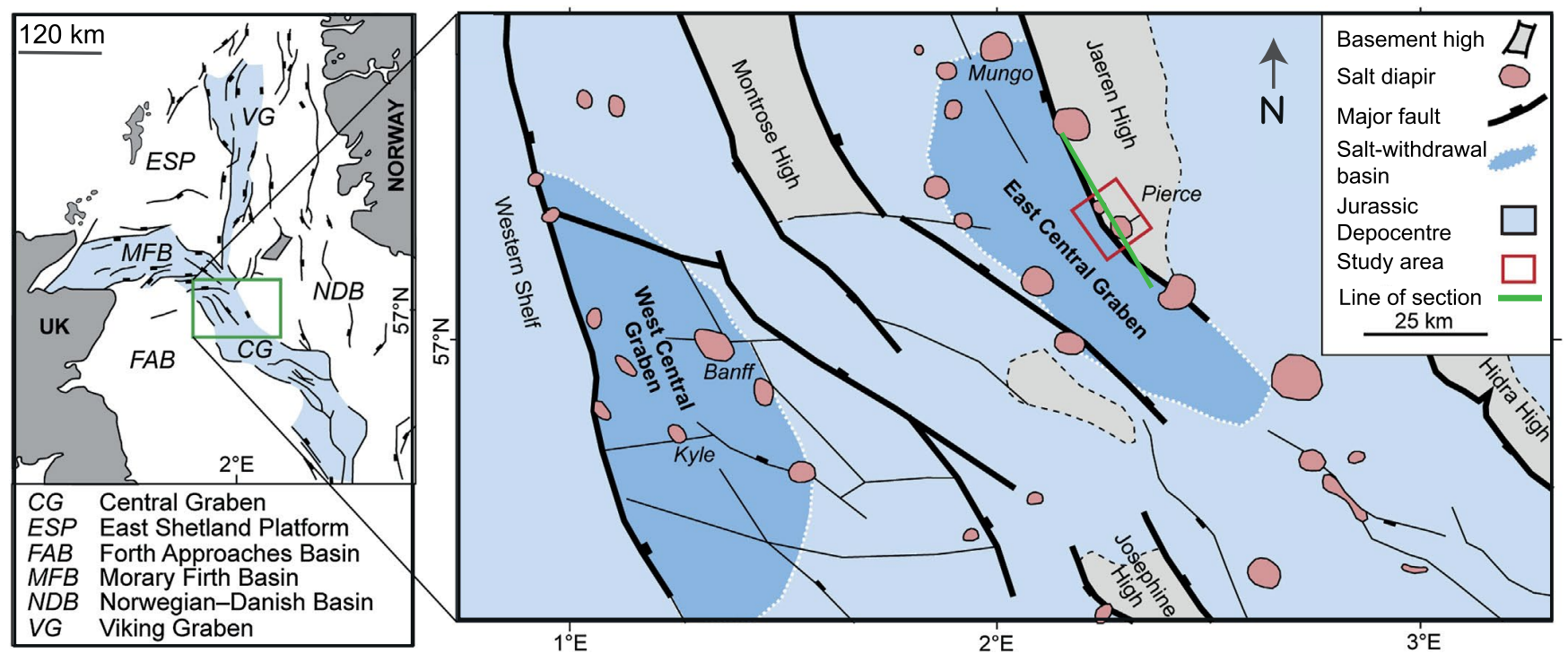

F I G U R E 10 Tectonic framework of the North Sea rift system, and structural map of the Central Graben showing the location of salt diapirs related to major basin faults and Jurassic salt withdrawal basins (Carruthers et al., 2013). Red box locates subsurface analogue used for comparison to models and green line locates Figure 11

In M3 (intermediate sedimentation rates), layers are initially non-extensive (S1), displaying early onlap and thinning (26.4\% at $0.023 \% / \mathrm{m}$; Table 3 ; Figures $9 \mathrm{~b}$ and $10 \mathrm{~b}$ ) similar to Eocene (orange) to Oligocene (peach) stratigraphy adjacent to the north Pierce diapir (Figure 11), which thin by $16 \%$ at $0.014 \% / \mathrm{m}$. Subsequent modelled layers (S2) are extensive but thin towards the diapir high $(60 \%$ at $0.04 \% / \mathrm{m}$; Table 3$)$, analogous to the Oligocene (peach) to Mid-Miocene (light peach) across north Pierce (65\% at $0.044 \% / \mathrm{m}$; Table S2; Figure 11c; Carruthers et al., 2013). In our simulations, $65 \%$ of the total thinning occurs between the flank and crestal locations, similar to subsurface observations of $85 \%$ of the total thinning around north Pierce occurring between the flank and the crest. After this initial modulation (S1, S2), subsequent M3 stratigraphy (S3) records a reduction in thinning rates and halokinetic influence on stratigraphy upwards (reduction from $60 \%$ to $23 \%$ total thinning: Table 3 ; Figures $9 \mathrm{~b}$ and $10 \mathrm{~b}$ ). This is also observed, albeit at a less extreme rate, between the Middle Miocene and Pliocene interval around the Pierce diapirs (reduction from $65 \%$ to $49 \%$ total thinning; Table S2; Figure 11). Much of the excess thinning in the Pierce example, compared to the model, occurs between the undeformed and flank position $(28 \%$ of thinning, compared to 6\% in M3; Tables 3 and Table S2). This is likely due to Cenozoic compressional forces driving diapir growth and upturn of stratigraphy (Birch \& Haynes, 2003; Carruthers et al., 2013; Scott et al., 2010), resulting in a less gradual reduction in halokinetic alteration upwards with respect to M3.

Based on this comparison of the lateral extent of layers, it is possible to infer that these examples represent intermediate sedimentation rates, relative to diapir rise rate. Sedimentation volumes for the Eocene to Oligocene are ca. $4,000 \mathrm{~km}^{3} / \mathrm{Myr}$, lower than for the Top Cretaceous-Eocene. This suggests that the overall diapir rise rate had been slower during the Eocene to Oligocene, with respect to the Top Cretaceous-Eocene time, giving a stratigraphic architecture typical of lower diapir rise rates relative to sedimentation rates (Carruthers et al., 2013).

In M5 (increasing sedimentation rate), S1 and early S2 are initially isolated on either side of the diapir in saltwithdrawal basins and onlap salt-cored topography (Table 3). Late S2 stratigraphy is extensive across the model, thinning towards the topographic high, with modulation decreasing up-stratigraphy (S3, Figure 9d). When combining the Cretaceous to Eocene (M2 analogue, Figure 11) and Eocene to Mid-Miocene (M3 analogue) stratigraphy adjacent to the Pierce diapirs, we observe an increasing-upwards sedimentation rate, relative to diapir rise rate (Den Birch \& Haynes, 2003; Hartog Jager et al., 1993; Jennette et al., 2000; Kilhams et al., 2014). The Cretaceous to Eocene was deposited when sedimentation rate < diapir rise rate, leading to the isolation of salt withdrawal basins and onlapping of the diapir flanks (S1, M5, Figure 11d; Carruthers et al., 2013). The Eocene - Mid Miocene (S2 equivalents) were likely deposited when sedimentation rates were higher relative to diapir rise rates, or when salt supply was equal to sedimentation rate (S2, M5, Figure 11d; Carruthers et al., 2013). Subsequent layers (Mid-Miocene - Pleistocene) are broadly extensive across the diapirs, similar to S3 in M5. The sedimentation volume for this interval is fairly low (ca. 2,000 $\mathrm{km}^{3}$ /Myr; Liu \& Galloway, 1997), so this observed reduction in halokinetic influence upwards is likely driven by a slowing or cessation of diapir growth rather than being driven 


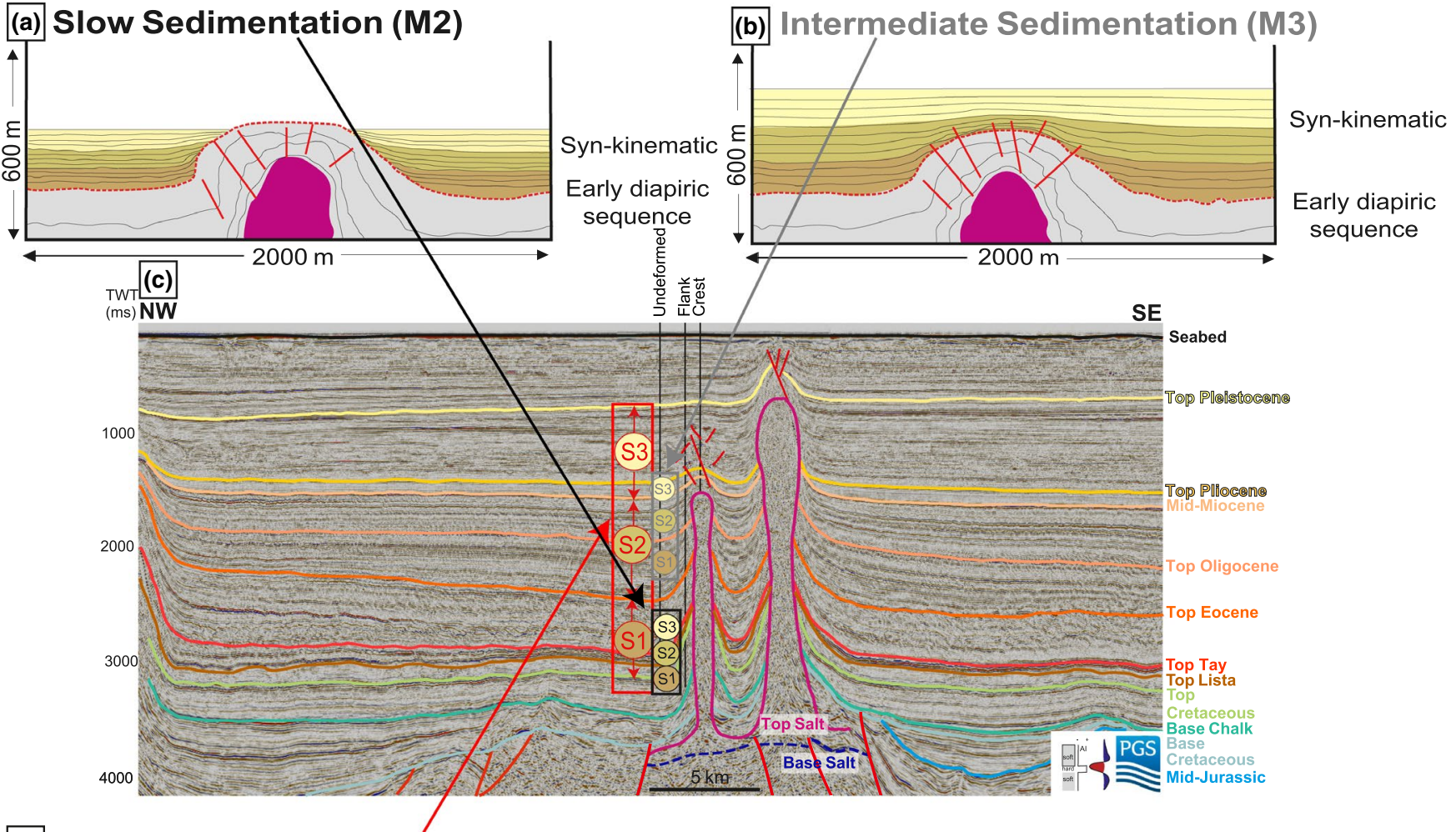

(d) Increasing Sedimentation (M5)
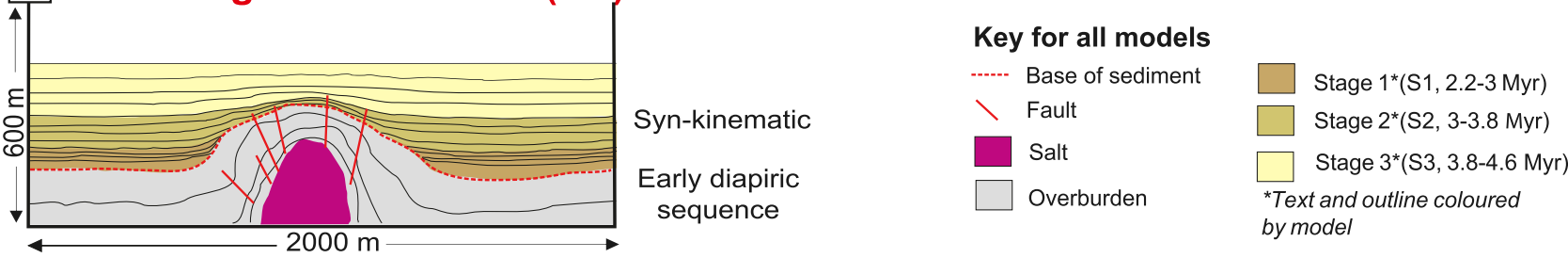

F I G U RE 11 Subsurface example of model application comparing some of the modelled results to stratigraphy from the Pierce Field, Eastern Central Graben, UK North Sea. (a, b and d) Models 2, 3 and 5 are analogous to different parts of the stratigraphy around the Pierce diapirs. (c) Interpreted time-migrated seismic profile across the Pierce diapirs. S1, S2, S3 highlight the likely sequences for comparison to models. The colour of the text represents which model those packages could represent (e.g. red represents M5). The location of the undeformed, flank and crest stratigraphic locations used for thinning rate calculations are shown for north Pierce and are the same spacing as those used for model calculations (Figure 5; Table 3). Thinning values are calculated in Table S2. Seismic data courtesy of PGS (MegaSurvey Plus 3D seismic data) from Cumberpatch, Finch, et al. (2021)

purely by high sedimentation rates (Carruthers et al., 2013). Pliocene to Pleistocene stratigraphy is extensive across north Pierce (S2 and S3, M5), but only the Pleistocene is present extensively across south Pierce, due to differential diapir growth histories and cessations (Carruthers et al., 2013; Scott et al., 2010). The upwards reduction in sedimentary thinning observed in the increasing sedimentation model (61\% in S2 to $22 \%$ in S3) is similar to that observed between the Eocene to Mid-Miocene (88\%) and the Mid-Miocene to Pleistocene (18\%) in the subsurface example, highlighting the potential applicability of the results from our models. Whereas these subsurface thinning rates are similar to those in our models, it is important to note that our models do not take into account erosion, or periods of non-deposition once sedimentation begins at 2.2 Myr. Therefore, in nature, 'apparent thinning' could be derived from periods of erosion, removing stratigraphy and generating halokinetic unconformities. This is particularly noticeable at the Mid-Miocene unconformity where 'thinning' is at least partly accommodated by Cenozoic compression rejuvenating diapir growth and increasing diapir rise rate, causing erosion of the diapirs overburden, without a variation in sedimentation rate (Carruthers et al., 2013). Our models generate realistic halokinetic unconformities, with variable bedding orientations between the early diapiric sequence and the syn-kinematic sequence due to a period of uplift and non-deposition prior to the commencement of sedimentation (Figure 8).

In nature, halokinetic sequence architecture is controlled by the dynamic ratio between sedimentation rate and diapir rise rate (e.g. Giles \& Rowan, 2012; Pichel \& Jackson, 2020), 
such that an 'apparent' increase in sedimentation (reducing halokinetic influence upwards) could represent a slowing of diapir growth due to regional tectonic quiescence or depletion of the salt source layer. Our observations and comparison to DEMs with variable sedimentation rates are consistent with diapir rise to sedimentation rate ratios derived from halokinetic sequence studies (Carruthers et al., 2013). The role halokinesis plays in shaping the stratigraphic architecture of the north and south Pierce diapirs is reduced from the Oligocene and Pliocene respectively, due to source layer depletion, resulting in halokinetic bathymetry being gradually buried (Figure 11; Birch \& Haynes, 2003). Integration of, and comparison between, DEM and subsurface data, demonstrates the importance of understanding local (salt layer variations) and regional (tectonic and sedimentation rate) controls when disentangling salt basin evolution.

\subsection{2 | Comparison to outcrop: Stratigraphy around the Bakio diapir, northern Spain}

The model simulations presented here document stratigraphic architectures and structural deformation, but do not invoke a specific sedimentary environment. Different compositions (e.g. carbonate or siliciclastic) and sedimentary environments (e.g. fluvial or deep-water) will respond differently to salt influence (Adams \& Kenter, 2012). In our models, slow sedimentation (M2) leads to the natural exposure of the early diapiric sequence above the diapir in the absence of a syn-kinematic cover or roof (Figure 5). This is likely to be common in marginal marine or terrestrial environments, where field data indicate the crest is often exposed, eroded and reworked into the syn-kinematic succession (Banham \& Mountney, 2013a, 2013b, 2014; Counts \& Amos, 2016; Counts et al., 2019; Giles \& Rowan, 2012; Ribes et al., 2015, 2017). If accommodation is continually available above diapir, as is the case in deep-water environments, a pelagic drape will likely cap the diapir, whereas coarser-grained deposition will be restricted to the flanks (Cumberpatch, Kane, et al., 2021; Giles \& Rowan, 2012; Poprawski et al., 2014, 2016; Rowan et al., 2003). Our models are applicable to all depositional environments, but fundamental controls on depositional architecture (e.g. accommodation, sedimentary processes) must not be overlooked.

Below, we compare the observations of M5 (increasing sedimentation) to a well-exposed halokinetically influenced deep-water succession and describe how integrating DEM results with outcropping examples can help reduce uncertainty in subsurface energy reservoir prediction.

Exposed Aptian-Cenomanian strata adjacent to the Bakio Diapir, northern Spain document an increase in sedimentation rate associated with an increase in erosion of the hinterland (Figure 12; García-Mondéjar, 1996; MartínChivelet et al., 2002; Puelles et al., 2014), similar to M5 increasing from 'slow' to 'fast' relative sedimentation rates. The resulting progradational pattern manifests in the deepwater succession as an upward change from thin-bedded low-density turbidites, deposited in the lobe fringe, (equivalent to S1) to thick-bedded high-density turbidites deposited in a lobe axis (equivalent to S3) (Cumberpatch, Kane, et al., 2021). Early diapiric (the Urgonian Group: Figure 12) and syn-kinematic (the Black Flysch Group) depositional elements are deformed closest to the diapir, and deformation intensity decreases away from the diapir, being minimal outside the halokinetically influenced sequence (ca. $700 \mathrm{~m}$ wide either side at Bakio); this observation is consistent with the predictions of our model (Figures 6 and 12). Outside the zone of halokinetic deformation, strata look similar to those deposited in an unconfined, salt-free setting, in terms of their architecture and facies distributions (e.g. Prélat et al., 2009: Figure 12d).

The Aptian-Albian was initially isolated on either side of the diapir, representing relatively slow sediment accumulation rates with respect to diapir growth. Individual thin beds representing distal deposition thin (by up to $1 \% / \mathrm{m}$; Figure 12e) and pinch out towards the salt-cored topographic high, in accordance with layers A-D in the increasing sedimentation model (S1, Figure 12) or the entirety of the slow sedimentation model (M2) (Cumberpatch, Finch, et al., 2021; Cumberpatch, Kane, et al., 2021). At Bakio, different sediment routing systems develop when stratigraphy is restricted to either side of the diapir due to different controls on deposition (Cumberpatch, Kane, et al., 2021). Under increasing sedimentation rates, the Albian-Cenomanian (Black Flysch Group: Figure 12) stratigraphy is laterally extensive, representing 'intermediate' sedimentation conditions in our model (S2 in M5 and the entirety of M3). However, rather than simply representing high sedimentation rates, as might be inferred from our numerical models, this stratal architecture likely reflects both an increased sediment supply from the Landes Massif (García-Mondéjar, 1996; Martín-Chivelet et al., 2002; Puelles et al., 2014) and a reduction in salt rise rate (Poprawski et al., 2014, 2016; Roca et al., 2021). In the field, this stratigraphy shows a reduction in the numbers of mass transport deposits (MTD) upwards, which cannot be resolved in the models, but can be compared to the decrease in stratigraphic dip upwards (from $12^{\circ}$ to $2^{\circ}$ between layer $\mathrm{E}$ and I, Figure 8), reducing instability. The lower Black Flysch stratigraphy shows a reduction in halokinetic deformation and thinning rate upwards (S2) that is comparable to modelled results, where thinning rates decrease from $0.053 \%$ to $0.006 \% / \mathrm{m}$ through time. Eventual deposition of the upper Black Flysch Group, across the diapir, akin to relatively high sedimentation rates in our model (S3 in M5 or the entirety of 


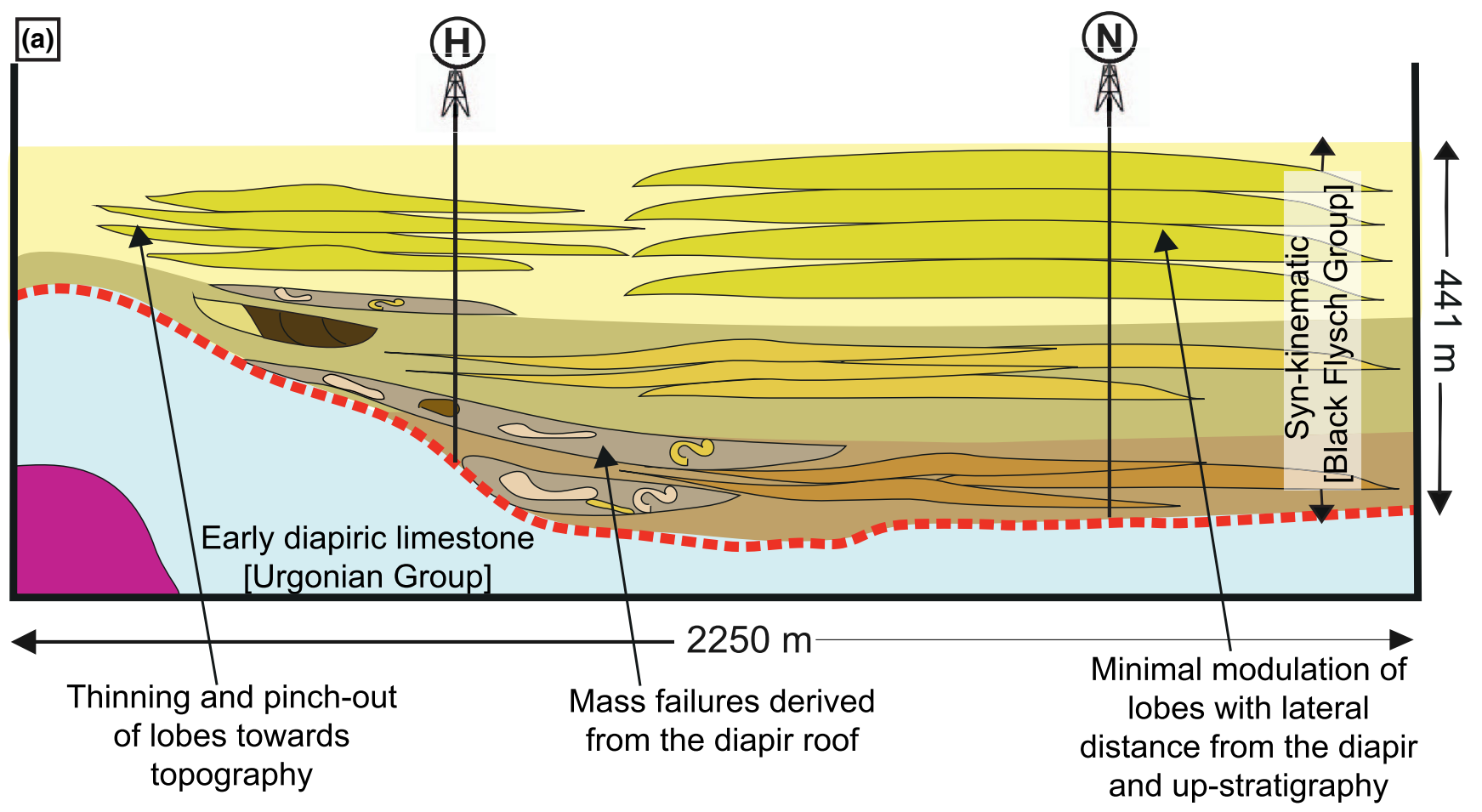

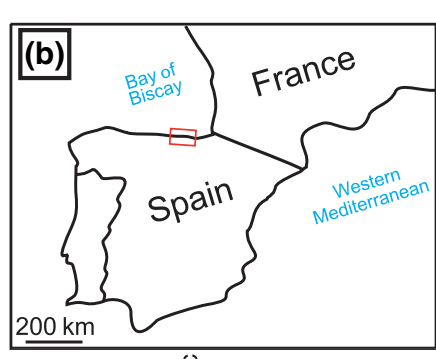
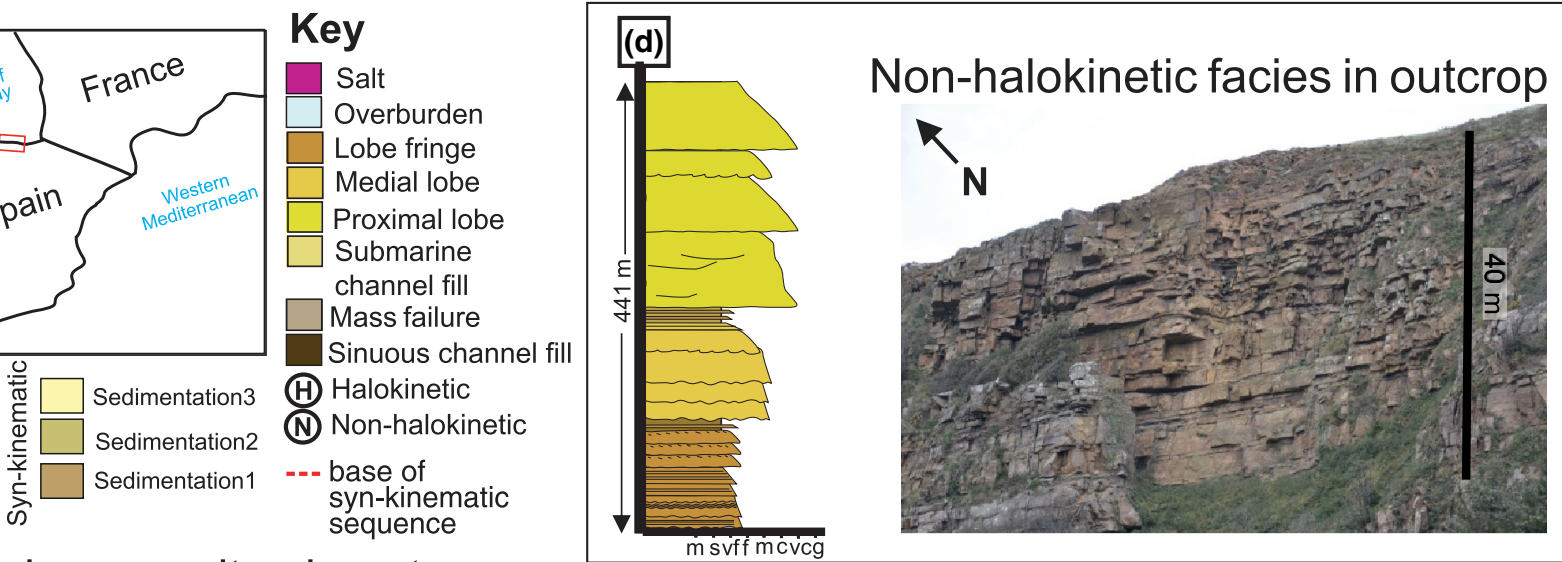

(c) Triassic evaporites in outcrop

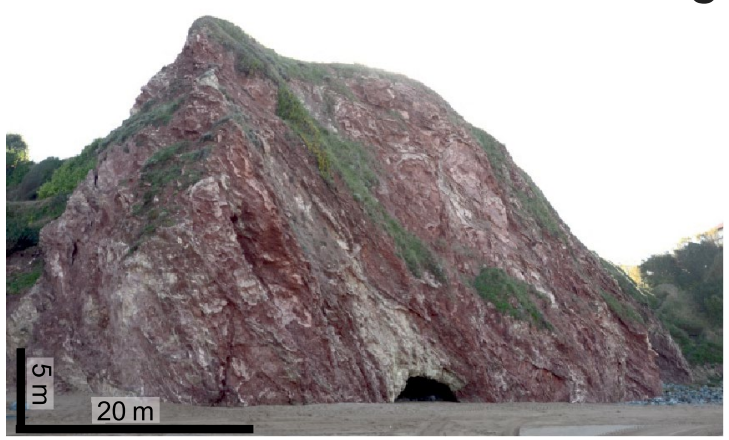

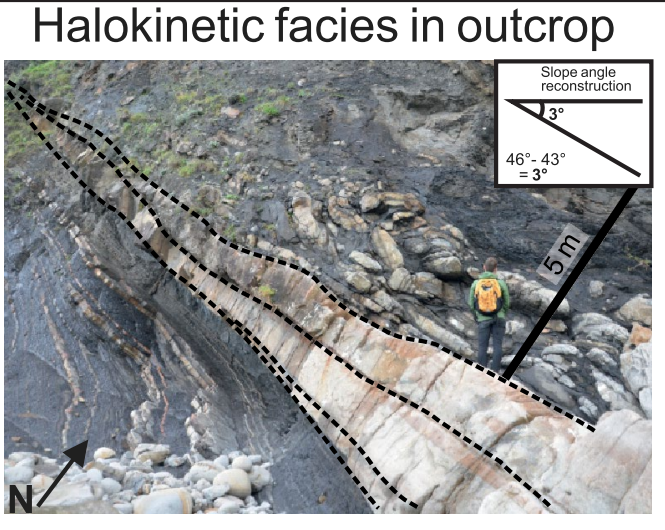

F I G U RE 12 Conceptual facies diagram for a deep-water succession based on the integration of field-based facies analysis around the Bakio diapir, Basque Cantabrian Basin, Northern Spain (see Cumberpatch, Kane, et al., 2021 for summary), overlain onto the result of M5. (a) Interpretation for deep-water facies (based on field facies analysis) overlain on the upper part of the increasing sedimentation model (located in Figure 6). Syn-kinematic layers from the model are grouped (S1-S3) and coloured, and depositional elements derived from field studies are overlain to show facies variability. $\mathrm{H}$ and $\mathrm{N}$ are theoretical stratigraphic profiles in the halokinetically influenced and non-halokinetically influenced zones, respectively. (b) Location map of the field analogue, for a full geological discussion, see Cumberpatch, Kane, et al. (2021). (c) Outcropping Triassic evaporites on Bakio Beach, believed to be part of the Bakio Diapir. (d) Non-halokinetic succession showing a classic progradational deep-water system (controlled by allogenic and autogenic processes), accompanied by an example of non-halokinetically influenced strata from the field. (e) Halokinetic stratigraphic profile showing a thinner, modulated succession that is rich in MTDs, accompanied by a field analogue of an outcrop-scale bed pinch out and an overlying MTD 


\section{Example of Halokinetic Zonation (M3)}

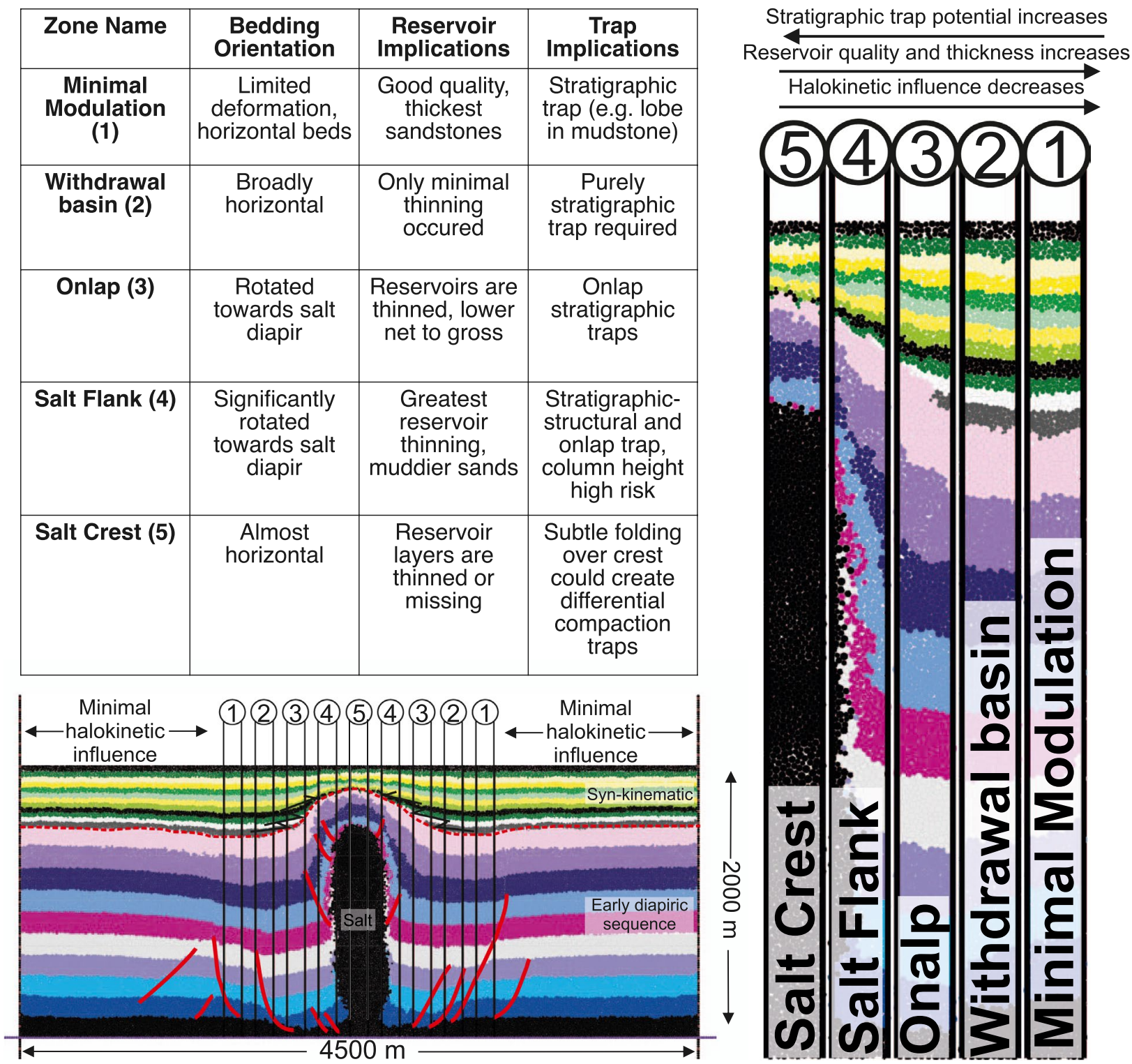

F I G U RE 13 Halokinetic zonation scheme shown for M3. The model is divided into five zones, four of which experience some form of halokinetic influence. Minimal deformation zones 1 and all stratigraphy outside of it show virtually no modulation by salt diapirism. Halokinetic influence increases towards the diapir-cored high, and changes from minor thickness changes in the 'withdrawal basin' zone to onlap and abrupt pinch out in the 'onlap' and 'salt flank' zones. Thinned and reduced stratigraphy are observed over the diapirs crest. The table highlights that while stratigraphic trap quality may be greater closer to the diapir, reservoir thickness and quality are likely higher further from the diapir, showing a 'trade-off' exists for subsurface energy exploration and production. Similar zonation is possible for all models

M4) heals the remnant diapiric topography, and shows almost no halokinetic influence (in similarity to layers $\mathrm{I}-\mathrm{L}$ in the increasing sedimentation model), except for its depositional location within remnant diapiric topography (Cumberpatch, Finch, et al., 2021). The relative increase in sedimentation rate at Bakio is driven primarily by an increase in sediment supply due to the uplifting source area, which is comparable to M5. However, a coeval reduction of salt supply due to welding between the Bakio and Guernica diapirs cannot be ruled out (Cumberpatch, Kane, et al., 2021; Poprawski et al., 2014, 2016; Roca et al., 2021).

In the syn-kinematic stratigraphy, particularly those equivalent to S2 in M5, thick-bedded sandstones deposited in channels and lobes dominate topographic lows, where sedimentary flows were focussed around salt-cored topographic relief (Figure 12d; Doughty-Jones et al., 2017, 2019; Mayall et al., 2010; Rodriguez et al., 2020; Sylvester et al., 2012). Towards the highs, the lower-density part of the 
flows may run-up topography depositing thinly bedded muddier sandstones towards the pinch out (Figure 12e; Kneller \& McCaffrey, 1999; Soutter et al., 2019). At Bakio, crestal deposition is assumed to be limited to a thin pelagic drape during $\mathrm{S} 1$ and much of $\mathrm{S} 2$ due to elevation, which is comparable to M5, often leading to remobilisation and the formation of MTDs. During S3 halokinetic bathymetry is healed, and crestal deposition is extensive, with minimal modulation (the upper Black Flysch Group).

\section{2 | Implications for subsurface energy}

Despite advances in extent and resolution of 3D seismic reflection imaging, the salt-sediment interface remains difficult to image, yet determining its position and precise geometry is crucial in helping to appraise stratigraphic-structural traps for hydrocarbon, carbon storage, and geothermal prospects globally (Jones \& Davison, 2014; Warren, 2016). Utilising outcrop analogues (Figure 12) can help provide sub-seismic scale depositional facies information, helping reduce uncertainty in reservoir quality and distribution. Numerical modelling results do not represent specific analogue conditions nor a 'snapshot' in time, and they can, therefore, help to quickly identify generic depositional architectures, deformation patterns and sediment thickness relationships as a function of several forcing parameters, such as variations in sedimentation rates.

Using stratigraphic architectures from our DEM and sedimentological data from field examples, we can improve predictions of the likely architecture of syn-kinematic stratigraphy and sedimentology around salt structures, which are poorly imaged in seismic reflection data. Understanding this requires a multi-scalar and multi-technique approach. For example, models provide details about gross thickness changes and geometry, whereas field analogues enable inferences about reservoir quality and net-to-gross.

\subsection{1 | Depositional reservoir quality}

Regardless of the amount of sedimentation, our models show that stratigraphy thins as it approaches the diapir, suggesting a reduction in the amount of total reservoir close to the structure (Figures 8 and 13; Jackson \& Hudec, 2017). Siliciclastic depositional environments show a thinning of sandstone towards the topographic high and an overall concentration of high reservoir quality units at the base of topography (Figure 12a,d), such that a salt-related combined structural-stratigraphic trapping mechanism becomes unlikely (Figure 13; Kane et al., 2012; Stricker et al., 2018). Muddier (lower reservoir quality) and thinner (lower netto-gross) units are expected closer to the diapir (Figures 8, 10e and 11; Banham \& Mountney, 2013a; Cumberpatch, Kane, et al., 2021). These units are more likely to be overpressured due to upward rotation, creating a large pressure head, with the top seal rocks unable to hold back a significant hydrocarbon column (Figure 13; Heidari et al., 2017, 2019; Nikolinakou et al., 2014a, 2014b, 2018). In carbonate environments, shallow platform or reef facies with excellent reservoir potential may be present over salt highs (e.g. Burgess et al., 2013; Riding, 2002; Teixell et al., 2017). As salt growth continues, fractures are generated in the overburden, which could form significant secondary porosity within the carbonate reservoirs, increasing quality and producibility (He et al., 2014; Howarth \& Alves, 2016; Saura et al., 2016).

Supplementing subsurface data with modelled stratal architectures and depositional facies observations from exhumed halokinetically influenced settings globally (e.g. Banham \& Mountney, 2013a, 2013b, 2014; Counts \& Amos, 2016; Counts et al., 2019; Cumberpatch, Kane, et al., 2021; Poprawski et al., 2014; 2016; Ribes et al., 2015, 2017) is recommended as a useful workflow for building reservoir models for salt basins with limited data. Observations from multiple scales and types of models can be combined to further reduce the uncertainty associated with reservoir quality prediction, for example, recent FEM has shown porosity is lower than expected near the vertical parts of salt structures and higher than expected at the base of diapirs, due to mean principal stress variations (Nikolinakou et al., 2014a).

\subsection{2 | Halokinetic zonation}

The model results show that a deformation zone exists on either side of the diapir in all experiments (Figures 4-6). Outside of this zone, the syn-kinematic and early diapiric stratigraphy are undeformed (Figure 13). The extent of this salt withdrawal basin is $1,150 \mathrm{~m}$ on either side of the diapir $(2,300 \mathrm{~m}$ in total). Therefore, the total zone of halokinetic influence in all models is approximately three times the original diapirs' maximum width $(750 \mathrm{~m})$, with a deformed zone of 1.5 diapir widths on either side of the structure. The width of the deformation zones is comparable across all models (Figure 7), and therefore it is shown that sedimentation rate is unlikely to have a significant control on the width of the zone of halokinetic influence (Giles \& Rowan, 2012; Hearon et al., 2014). Other factors such as salt supply, salt viscosity, and style and magnitude of regional tectonics (which are not modelled) will in nature, influence the width of the halokinetically deformed zone (Fuchs et al., 2011; Koyi, 1998). The model can be further divided into zones based on onlap geometry and thinning rates, which highlight the 'trade off' between reservoir thickness and stratigraphic trap potential in subsurface plays (Figure 13). In the flank locations, bedding dips and thinning rates are shown to be greater under 
slower sedimentation rates compared to higher sedimentation rates (Figure 8; Table 3), which is important when predicting hydrocarbon column height. Significant overpressures on reservoirs below can be created by fast sedimentation rates (Figures 7 and 8; Peeters et al., 2018).

\subsection{3 | Fault distribution}

Radial faults associated with salt diapirs are shown to cause the compartmentalisation of reservoirs (Birch \& Haynes, 2003; Charles \& Ryzhikov, 2015; Coleman et al., 2018; Peeters et al., 2018; Scott et al., 2010). Our DEM replicates localised fault growth, evolution and propagation because the contacts between elements are treated as potential displacement surfaces. Our models all document a similar fault pattern, suggesting that faulting, and therefore fault compartmentalisation is not heavily influenced by sedimentation rate. As well as seismically resolvable faults, outcrop and borehole data indicate brittle deformation is significant in salt basins (e.g. Cumberpatch, Kane, et al., 2021; Koestler \& Ehrmann, 1991). Our DEM replicates this brittle deformation (Figures 4-6); as in nature, extreme thinning, and termination of layers are in part accommodated by small-scale displacements. Understanding sub-seismic scale fault distribution is important for predicting reservoir compartmentalisation and seal integrity in the subsurface. Faults, when sealing, could act as lateral permeability barriers, especially if the faults and surrounding reservoir rocks become cemented with salt and salt-related breccia (Li \& Urai, 2016; Van Bergen \& de Leeuw, 2001). DEM is, therefore, advantageous in predicting potential traps, conduits and baffles, due to its replication of diapir-related brittle deformation.

\section{3 | Future work}

The DEM presented here is useful for predicting regional trends and studying generic interactions of salt structures and stratigraphy but further work is required to recreate specific complicated salt geometries. Other suggestions for further development of this model are to incorporate reactivation and cessation of halokinesis, studying the impact on stratigraphic architectures and the development of halokinetic unconformities due to periods of diapiric rejuvenation, uplift, erosion and non-deposition. Incorporating erosion and remobilisation into the model would also more realistically represent natural settings where entrainment and failure influence thickness patterns, stratigraphic architectures and can remove the diapiric roof. Other investigations may include assessing the influence of evolving salt geometries relative to salt thickness. In nature, salt diapirs are rarely isolated structures, and therefore subsequent studies will focus on the interaction of multiple salt structures, with different growth histories on different sedimentary successions. Many of the limitations of the model described above, are due to its two-dimensional nature. The ultimate aim of future work is to develop a three-dimensional DEM to better understand the four-dimensional variability in halokinetically influenced stratigraphy and associated subsurface energy reservoirs.

\section{6 | CONCLUSIONS}

1. DEM can form an integral part of the workflow when studying salt-sediment interactions. Here, a DEM is used to study the variability in stratigraphic architecture and deformation patterns around a growing salt structure under different sedimentation rates.

2. The models generate realistic salt-related faults. In all models, structural deformation and extent of halokinetic influence are similar, and syn-kinematic strata, at least initially, are isolated to either side of the diapir, thinning and onlapping towards the high.

3. Under slow sedimentation rate (M2) deposition is restricted to salt withdrawal basins on either side of the diapir throughout evolution, while in M3-M6 sedimentation eventually occurs over the diapir crest, often associated with significant lateral thickness variability. Diapir growth is most inhibited under fast aggradation (M4) and the halokinetic influence on stratigraphy reduces quickly with time.

4. Thinning of syn-kinematic stratigraphy from the undeformed section to the diapir flanks is greatest under slow aggradation (M2, 34\%), and least under fast aggradation (M4, 12\%). In all models, thinning is about six times greater between the salt flank and crest, compared to the undeformed section and the salt flank, indicating more intense deformation close to the diapir.

5. Thinning rate decreases through time (up stratigraphy), showing a reduction of halokinetic modulation with increased sediment thickness, as halokinetic bathymetry is 'healed'. This is true for all models except for decreasing sedimentation (M6), which experiences a slight increase in stratigraphy.

6. Our simplified two-dimensional models provide useful analogues for salt-influenced basins with complicated four-dimensional evolutions. Natural examples record the interplay between sedimentation rate and diapir rise rate, whilst models isolate and vary sedimentation rate. Comparison to the Pierce field diapirs, North Sea, shows how different models can be applicable to different parts of stratigraphy and suggest how interpreters could infer likely sedimentation rates and conditions from subsurface stratigraphic geometries. 
7. Facies, and thus reservoir distribution, around salt diapirs will differ from unconfined settings due to halokinetic modulation, both vertically and laterally. A deep-water analogue from stratigraphy adjacent to the Bakio diapir shows that halokinetically influenced facies (e.g. the salt flank) contain thin beds, sandstone pinch outs and increased mass transport deposits in comparison with the allogenic deposits (e.g. the undeformed zone), which are difficult to decipher from deep-water strata in non-salt influenced settings.

8. Integrating DEM with subsurface and outcrop data helps to reduce reservoir and trap uncertainty in subsurface energy exploration and development.

\section{ACKNOWLEDGEMENTS}

This paper contains work conducted during ZCs' $\mathrm{PhD}$ study undertaken as part of the Natural Environment Research Council (NERC) Centre for Doctoral Training (CDT) in Oil \& Gas [grant number NEM00578X/1]. We thank PGS for permission to publish an image extracted from MegaSurvey Plus 3D seismic data. Christopher Brennan and Evey Gannaway Dalton are thanked for their constructive and detailed reviews which improved the manuscript. Associate Editor Craig Magee is thanked for his additional comments and the timely handling of the manuscript.

\section{CONFLICT OF INTEREST}

The authors have no conflict of interest to declare.

\section{PEER REVIEW}

The peer review history for this article is available at https:// publons.com/publon/10.1111/bre.12569

\section{DATA AVAILABILITY STATEMENT}

The data that supports the findings of this study are available in the supplementary material of this article. Animated gifs of all model simulations used in Figure 3-6 are available at https://doi.org/10.48420/14701203

\section{ORCID}

Zoё A. Cumberpatch (D) https://orcid. org/0000-0001-8253-8418

\section{REFERENCES}

Abe, S., \& Urai, J. L. (2012). Discrete element modelling of boudinage: Insights on rock rheology, matrix flow, and evolution of geometry. Journal of Geophysical Research Solid Earth, 117. https://agupu bs.onlinelibrary.wiley.com/doi/full/10.1029/2011JB008555.

Abe, S., van Gent, H., \& Urai, J. L. (2011). DEM simulation of normal faults in cohesive materials. Tectonophysics, 512, 12-21. https://doi. org/10.1016/j.tecto.2011.09.008
Adams, E., \& Kenter, J. (2012). So different, yet so similar: Comparing and contrasting siiciclastic and carbonate slopes. AAPG Search and Discovery, Article 50683.

Albertz, M., \& Ings, S. J. (2012). Some consequences of mechanical stratification in basin-scale numerical models of passive margin salt tectonics. In G. I. Alsop, S. G. Archer, A. J. Hartley, N. T. Grant, \& R. Hodgkinson (Eds.), Salt tectonics, sediments and prospectivity (Vol. 363, pp. 303-330). Geological Society, London, Special Publications.

Allen, M. P., \& Tildesley, D. J. (1987). Molecular simulation of liquids. Clarendon.

Andrews, B. J., Cumberpatch, Z. A., Shipton, Z. K., \& Lord, R. (2020). Collapse processes in abandoned pillar and stall coal mines: Implications for shallow mine geothermal energy. Geothermics, 88 , 101904. https://doi.org/10.1016/j.geothermics.2020.101904

Banham, S. G., \& Mountney, N. P. (2013a). Evolution of fluvial systems in salt-walled mini-basins: A review and new insights. Sedimentary Geology, 296, 142-166. https://doi.org/10.1016/j. sedgeo.2013.08.010

Banham, S. G., \& Mountney, N. P. (2013b). Controls on fluvial sedimentary architecture and sediment-fill state in salt-walled mini-basins: Triassic Moenkopi Formation, Salt Anticline Region, SE Utah, USA. Basin Research, 25, 709-737. https://doi.org/10.1111/bre.12022

Banham, S. G., \& Mountney, N. P. (2014). Climatic versus halokinetic control on sedimentation in a dryland fluvial succession. Sedimentology, 61, 570-608. https://doi.org/10.1111/sed.12064

Belheine, N., Plassiard, J. P., Donzé, F. V., Darve, F., \& Seridi, A. (2009). Numerical simulation of drained triaxial test using 3D discrete element modeling. Computers and Geotechnics, 36, 320-331. https://doi.org/10.1016/j.compgeo.2008.02.003

Benseghier, Z., Cuéllar, P., Luu, L. H., Bonelli, S., \& Philippe, P. (2020). A parallel GPU-based computational framework for the micromechanical analysis of geotechnical and erosion problems. Computers and Geotechnics, 120, 103404. https://doi.org/10.1016/j.compg eo.2019.103404

Berton, F., \& Vesely, F. F. (2016). Seismic expression of depositional elements associated with a strongly progradational shelf margin: Northern Santos Basin, southeastern Brazil. Brazilian Journal of Geology, 46(4), 585-603. https://doi.org/10.1590/2317-4889201620160031

Birch, P., \& Haynes, J. (2003). The Pierce field blocks 23/22a, 23/27, UK North Sea. Geological Society, London, Memoir, 20, 618-647. https://doi.org/10.1144/GSL.MEM.2003.020.01.51

Bonini, M. (2003). Detachment folding, fold amplification, and diapirism in thrust wedge experiments. Tectonics, 22(6), 1065. https://doi. org/10.1029/2002TC001458

Booth, J. R., Dean, M. C., Duvernay, A. E., \& Styzen, M. J. (2003). Paleo-bathymetric controls on the stratigraphic architecture and reservoir development of confined fans in the Auger Basin: Central Gulf of Mexico slope. Marine and Petroleum Geology, 20, 563-586. https://doi.org/10.1016/j.marpetgeo.2003.03.008

Botter, C., Cardozo, N., Hardy, S., Lecomte, I., \& Escalona, A. (2014). From mechanical modelling to seismic imaging of faults: A synthetic workflow to study the impact of faults on seismic. Marine and Petroleum Geology, 57, 187-200.

Burgess, P. M. (2012) A brief review of developments in stratigraphic forward modelling, 2000-2009. In D. G. Roberts \& A. W. Bally, (Eds.), Regional geology and tectonics: Principles of geologic analysis (Vol. 1A, p. 864). Elsevier. 
Burgess, P. M., Winefield, P., Minozoni, M., \& Elders, C. (2013). Methods for identification of isolated carbonate buildups from seismic reflection data. AAPG Bulletin, 97(7), 1071-1098. https://doi. org/10.1306/12051212011

Carruthers, D., Cartwright, J., Jackson, M. P. A., \& Schutjens, P. (2013). Origin and timing of layer-bound radial faulting around North Sea salt stocks: New insights into the evolving stress state around rising diapirs. Marine and Petroleum Geology, 48, 130-148. https://doi. org/10.1016/j.marpetgeo.2013.08.001

Charles, R., \& Ryzhikov, K. (2015). Merganser field: Managing subsurface uncertainty during the development of a salt diapir field in the UK Central North Sea. In T. Mckie, P. T. S. Rose, A. J. Hartley, D. W. Jones, \& T. L. Armstrong (Eds.), Tertiary deep-marine reservoirs of the North Sea Region (Vol. 403, pp. 261-298). Geological Society Special Publication.

Chemia, Z., Koyi, H., \& Schmeling, H. (2008). Numerical modelling of rise and fall of a dense layer in salt diapirs. Geophysical Journal International, 172(2), 798-816.

Cil, M. B., \& Alshibli, K. A. (2012). 3D assessment of fracture of sand particles using discrete element method. Géotechnique Letters, 2(3), 161-166. https://doi.org/10.1680/geolett.12.00024

Coleman, A. J., Jackson, C.-L., Duffy, O. B., \& Nikolinakou, M. A. (2018). How, where, and when do radial faults grow near salt diapirs? Geology, 46(7), 655-658. https://doi.org/10.1130/G40338.1

Costa, E., \& Vendeville, B. C. (2002). Experimental insights on the geometry and kinematics of fold-and-thrust belts above weak, viscous evaporitic décollement. Journal of Structural Geology, 24, 17291739. https://doi.org/10.1016/S0191-8141(01)00169-9

Counts, J. W., \& Amos, K. J. (2016). Sedimentology, depositional environments and significance of an Ediacaran salt-withdrawal minibasin, Billy Springs Formation, Flinders Ranges, South Australia. Sedimentology, 63, 1084-1123. https://doi.org/10.1111/sed.12250

Counts, J. W., Dalgarno, C. R., Amos, K. J., \& Hasiotis, S. T. (2019). Lateral facies variability along the margin of an outcropping saltwithdrawal minibasin, South Australia. Journal of Sedimentary Research, 89, 28-45. https://doi.org/10.2110/jsr.2019.2

Cumberpatch, Z. A., Finch, E., \& Kane, I. A. (2021). External signal preservation in halokinetic stratigraphy: A discrete element modeling (DEM) approach. Geology. https://pubs.geoscienceworld.org/ gsa/geology/article/doi/10.1130/G48448.1/594892/External-signa 1-preservation-in-halokinetic.

Cumberpatch, Z. A., Kane, I. A., Soutter, E. L., Hodgson, D. M., Jackson, C.-A.-L., Kilhams, B. A., \& Poprawski, Y. (2021). Interactions of deep-water gravity flows and active salt tectonics. Journal of Sedimentary Research, 91, 34-65.

Daniilidis, A., \& Herber, R. (2017). Salt intrusions providing a new geothermal exploration target for higher energy recovery at shallower depths. Energy, 118, 658-670. https://doi.org/10.1016/j. energy.2016.10.094

Davison, I., Alsop, G. I., Evans, N. G., \& Safaricz, M. (2000). Overburden deformation patterns and mechanisms of salt diapir penetration in the Central Graben, North Sea. Marine and Petroleum Geology, 17, 601-618. https://doi.org/10.1016/S0264-8172(00)00011-8

Davison, I., Alsop, I., Birch, P., Elders, C., Evans, N., Nicholson, H., Rorison, P., Wade, D., Woodward, J., \& Young, M. (2000). Geometry and late-stage structural evolution of Central Graben salt diapirs, North Sea. Marine and Petroleum Geology, 17, 499-522. https://doi.org/10.1016/S0264-8172(99)00068-9

Davison, I., Insley, M., Harper, M., Weston, P., Blundell, D., Mcclay, K., \& Quallington, A. (1993). Physical modelling of overburden deformation around salt diapirs. Tectonophysics, 228, 255-274. https://doi.org/10.1016/0040-1951(93)90344-J

de Haas, H., Okkels, E., \& Van Weering, T. C. E. (1996). Recent sediment accumulation in the Norwegian Channel, North Sea. Norges Geologiske Unders $\phi$ kelse Bulletin, 430, 57-65.

Den Hartog Jager, D., Giles, M. R., \& Griffiths, G. R. (1993). Evolution of Paleogene sub-marine fans of the North Sea in space and time. In J. R. Parker (Ed.), Petroleum Geology of Northwest Europe: Proceedings of the 4th Conference, The Geological Society, London. (pp. 59-71).

Deng, C., Gawthorpe, R. L., Fossen, H., \& Finch, E. (2018). How does the orientation of a preexisting basement weakness influence fault development during renewed rifting? Insights from threedimensional discrete element modeling. Tectonics, 37(7), 22212242. https://doi.org/10.1029/2017TC004776

Donzé, F., Mora, P., \& Magnier, S.-A. (1994). Numerical simulation of faults and shear zones. Geophysical Journal International, 116, $46-52$.

Dooley, T. P., \& Hudec, M. R. (2017). The effects of base-salt relief on salt flow and suprasalt deformation patterns - Part 2: Application to the eastern Gulf of Mexico. Interpretation, 5(1), 25-38. https://doi. org/10.1190/INT-2016-0088.1

Dooley, T. P., Hudec, M. R., \& Jackson, M. P. (2012). The structure and evolution of sutures in allochthonous salt. AAPG Bulletin, 96(6), 1045-1070. https://doi.org/10.1306/09231111036

Dooley, T. P., Hudec, M. R., Pichel, L. M., \& Jackson, M. P. A. (2020). The impact of base-salt relief on salt flow and suprasalt deformation patterns at the autochthonous, paraautochthonous and allochthonous level: Insights from physical models. Journal of the Geological Society, Special Publications, 476(2), 287-315.

Dooley, T. P., Jackson, M. P., \& Hudec, M. R. (2009). Inflation and deflation of deeply buried salt stocks during lateral shortening. Journal of Structural Geology, 31(6), 582-600.

Dooley, T. P., Jackson, M. P. A., \& Hudec, M. R. (2013). Coeval extension and shortening above and below salt canopies on an uplifted, continental margin: Application to the northern Gulf of Mexico. AAPG Bulletin, 97(10), 1737-1764. https://doi.org/10.1306/03271312072

Dooley, T. P., Jackson, M. P. A., Jackson, C.-A.-L., Hudec, M. R., \& Rodriguez, C. R. (2015). Engimatic structures within salt walls of the Santos Basin - Part 2: Mechanical explanation from physical modelling. Journal of Structural Geology, 75, 163-187.

Doughty-Jones, G., Lonergan, L., Mayall, M., \& Dee, S. J. (2019). The role of structural growth in controlling the facies and distribution of mass transport deposits in a deep-water salt minibasin. Marine and Petroleum Geology, 104, 106-124. https://doi.org/10.1016/j.marpe tgeo.2019.03.015

Doughty-Jones, G., Mayall, M., \& Lonergan, L. (2017). Stratigraphy, facies, and evolution of deep-water lobe complexes within a salt controlled intraslope minibasin. AAPG Bulletin, 101, 1879-1904. https://doi.org/10.1306/01111716046

Duffy, O. B., Dooley, T. P., Hudec, M. R., Jackson, M. P. A., Fernandez, N., Jackson, C.-L., \& Soto, J. I. (2018). Structural evolution of salt-influenced fold-and-thrust belts: A synthesis and new insights from basins containing isolated salt diapirs. Journal of Structural Geology, 114, 206-221. https://doi.org/10.1016/j. jsg.2018.06.024

Duffy, O. B., Fernandez, N., Hudec, M. R., Jackson, M. P. A., Burg, G., Dooley, T. P., \& Jackson, C.-A.-L. (2017). Lateral mobility of minibasins during shortening: Insights from the SE Precaspian Basin, Kazakhstan. Journal of Structural Geology, 97, 257-276. https:// doi.org/10.1016/j.jsg.2017.02.002 
Dutta, U., Baruah, A., \& Mandal, N. (2016). Role of source-layer tilts in the axi-asymmetric growth of diapirs triggered by a Rayleigh-Taylor instability. Geophysical Journal International, 206, 1814-1830. https://doi.org/10.1093/gji/ggw244

Eldrett, J., Tripsanas, E., Davis, C., McKie, T., Vieira, M., Osterloff, P., \& Sandison, T. (2015). Sedimentological evolution of Sele Formation deep-marine depositional systems of the Central North Sea. Geological Society, London, Special Publications, 403, 63-98. https://doi.org/10.1144/SP403.9

Fernandez, N., Hudec, M. R., Jackson, C.-L., Dooley, T. P., \& Duffy, O. B. (2020). The competition for salt and kinematic interactions between minibasins during density-driven subsidence: Observations from numerical models. Petroleum Geoscience, 26(1), 3-15. https:// doi.org/10.1144/petgeo2019-051

Fernandez, N., \& Kaus, B. J. P. (2015). Pattern formation in 3-D numerical models of down-built diapirs initiated by a Rayleigh-Taylor instability. Geophysical Journal International, 202(2), 1253-1270. https://doi.org/10.1093/gji/ggv219

Ferrer, O., Mcclay, K., \& Sellier, N. C. (2017). Influence of fault geometries and mechanical anisotropies on the growth and inversion of hanging-wall synclinal basins: Insights from sandbox models and natural examples. Geological Society, London, Special Publications, 439(1), 487-509. https://doi.org/10.1144/SP439.8

Finch, E. (1998). A crustal lattice solid model: The evolution, geometry and scaling of tectonic extension ( $\mathrm{PhD}$ thesis). School of Environmental Sciences, University of Ulster.

Finch, E., \& Gawthorpe, R. (2017). Growth and interaction of normal faults and fault network evolution in rifts: Insights from three-dimensional discrete element modelling. Geological Society, London, Special Publications, 439, 219-248. https://doi. org/10.1144/SP439.23

Finch, E., Hardy, S., \& Gawthorpe, R. (2003). Discrete element modelling of contractional fault-propagation folding above rigid basement fault blocks. Journal of Structural Geology, 25(4), 515-528.

Finch, E., Hardy, S., \& Gawthorpe, R. (2004). Discrete-element modelling of extensional fault-propagation folding above rigid basement fault blocks. Basin Research, 16(4), 467-488.

Fuchs, L., Schmeling, H., \& Koyi, H. (2011). Numerical models of salt diapir formation by down-building: The role of sedimentation rate, viscosity contrast, initial amplitude and wave length. Geophysical Journal International, 186, 390-400. https://doi. org/10.1111/j.1365-246X.2011.05058.x

García-Mondéjar, J. (1996). Plate reconstruction of the Bay of Biscay. Geology, 24, 635-638. https://doi.org/10.1130/00917613(1996)024<0635:PROTBO>2.3.CO;2

Gaullier, V., \& Vendeville, B. C. (2005). Salt tectonics driven by sediment progradation: Part II - Radial spreading of sedimentary lobes prograding above salt. AAPG Bulletin, 89(8), 1081-1089. https:// doi.org/10.1306/03310503064

Gemmer, L., Beaumont, C., \& Ings, S. J. (2005). Dynamic modelling of passive margin salt tectonics: Effects of water loading, sediment properties and sedimentation patterns. Basin Research, 17, 382402. https://doi.org/10.1111/j.1365-2117.2005.00274.x

Gemmer, L., Ings, S. J., Medvedev, S., \& Beaumont, C. (2004). Salt tectonics driven by differential sediment loading: Stability analysis and finite-element experiments. Basin Research, 16, 199-218. https:// doi.org/10.1111/j.1365-2117.2004.00229.x

Giles, K., \& Lawton, T. (2002). Halokinetic sequence stratigraphy adjacent to the El Papalote diapir, Northeastern Mexico. AAPG Bulletin, $86,823-840$.
Giles, K., \& Rowan, M. (2012). Concepts in halokinetic-sequence deformation and stratigraphy. In G. I. Alsop, S. G. Archer, A. J. Hartley, N. T. Grant, \& R. Hodgkinson (Eds.), Salt tectonics, sediments and prospectivity (Vol. 363, pp. 7-31). Geological Society, London, Special Publications.

Grant, R. J., Underhill, J. R., Hernández-Casado, J., Barker, S. M., \& Jamieson, R. J. (2019). Upper Permian Zechstein Supergroup carbonate-evaporite platform palaeomorpology in the UK Southern North Sea. Marine and Petroleum Geology, 100, 484-518.

Grimstad, S. (2016). Salt tectonics in the central and northeastern Nordkapp Basin, Barents Sea (MS thesis, 127 p.). University of Oslo, Norway.

Hamilton-Wright, J., Dee, S., Von Nicolai, C., \& Johnson, H. (2019). Investigating controls on salt movement in extensional settings using finite-element modelling. Petroleum Geoscience, 25(3), 258-271. https://doi.org/10.1144/petgeo2018-119

Hardy, S., \& Finch, E. (2005). Discrete-element modelling of detachment folding. Basin Research, 17(4), 507-520. https://doi. org/10.1111/j.1365-2117.2005.00280.x

Hardy, S., \& Finch, E. (2006). Discrete element modelling of the influence of cover strength on basement-involved fault-propagation folding. Tectonophysics, 415, 225-238. https://doi.org/10.1016/j. tecto.2006.01.002

Harms, G. L. (2015). Numerical modelling of salt diapirism and the temperature field during thin-skinned extension; in search of geothermal and hydrocarbon energy sources (Master's thesis, p. 32). Utrecht University, the Netherlands.

He, L., Zhao, L., Li, J., Ma, J., Lui, R., Wang, S., \& Zhao, W. (2014). Complex relationship between porosity and permeability of carbonate reservoirs and its controlling factors: A case study of platform facies in Pre-Caspian Basin. Petroleum Exploration and Development, 41(2), 225-234. https://doi.org/10.1016/S1876 -3804(14)60026-4

Hearon, T. E., Rowan, M. G., Giles, K. A., \& Hart, W. H. (2014). Halokinetic deformation adjacent to the deepwater Auger diapir, Garden Banks 470, northern Gulf of Mexico: Testing the applicability of an outcrop-based model using subsurface data. Interpretation, 2(4). 57-76.

Heidari, M., Nikolinakou, M. A., Flemmings, P. B., \& Hudec, M. R. (2017). A simplified stress analysis of rising salt domes. Basin Research, 29(3), 363-376.

Heidari, M., Nikolinakou, M. A., Hudec, M. R., \& Flemings, P. B. (2016). Geomechanical analysis of a welding salt layer and its effects on adjacent sediments. Tectonophysics, 683, 172-181.

Heidari, M., Nikolinakou, M. A., Hudec, M. R., \& Flemmings, P. B. (2019). Influence of a reservoir bed on diapirism and drilling hazards near a salt diapir: A geomechanical approach. Petroleum Geoscience, 25(3), 282-297. https://doi.org/10.1144/petgeo2018-113

Hodgson, N. A., Farnsworth, J., \& Fraser, A. J. (1992). Salt-related tectonics, sedimentation and hydrocarbon plays in the Central Graben, North Sea, UKCS. In R. F. P. Hardman (Ed.), Exploration Britain: Geological insights for the next decade (Vol. 67, pp. 31-63), Geological Society, London, Special Publications.

Hossain, S. (2020). Application of seismic attribute analysis in fluvial seismic geomorphology. Journal of Petroleum Exploration and Production Technology, 10(3), 1009-1019.

Howarth, V., \& Alves, T. M. (2016). Fluid flow through carbonate platforms as evidence for deep-seated reservoirs in Northwest Australia. Marine Geology, 380, 17-43. https://doi.org/10.1016/j. margeo.2016.06.011 
Howlett, D. M., Gawthorpe, R. L., Ge, Z., Rotevatn, A., \& Jackson, C.-A.-L. (2021). Turbidites, topography and tectonics: Evolution of submarine channel-lobe systems in the salt-influenced Kwanza Basin, offshore Angola. Basin Research, 33, 1076-1110.

Hudec, M., \& Jackson, M. (2007). Terra infirma: Understanding salt tectonics. Earth-Science Reviews, 82, 1-28. https://doi.org/10.1016/j. earscirev.2007.01.001

Hudec, M. R., \& Jackson, M. P. A. (2011). The salt mine: A digital atlas of salt tectonics. Bureau of Economic Geology Udden book series, no. 5; AAPG Memoir, 99 (p. 305). Bureau of Economic Geology, Jackson School of Geosciences, University of Texas at Austin; American Association of Petroleum Geologists.

Hudec, M., Norton, I. O., Jackson, M. P. A., \& Peel, F. J. (2013). Jurassic evolution of the Gulf of Mexico salt basin. AAPG Bulletin, 97(10), 1638-1710. https://doi.org/10.1306/04011312073

Imber, J., Tuckwell, G. W., Childs, C., Walsh, J. J., Manzocchi, T., Heath, A. E., Bonson, C. G., \& Strand, J. (2004). Three-dimensional distinct element modelling of relay growth and breaching along normal faults. Journal of Structural Geology, 26, 1897-1911. https:// doi.org/10.1016/j.jsg.2004.02.010

Ismail-Zadeh, A. T., Talbot, C. J., \& Volozh, Y. A. (2001). Dynamic restoration of profiles across diapiric salt structures: Numerical approach and its applications. Tectonophysics, 337, 23-38. https://doi. org/10.1016/S0040-1951(01)00111-1

Ismail-Zadeh, A. T., Tsepelev, I., Talbot, C., \& Korotkii, A. (2004). Three-dimensional forward and backward modelling of diapirism: Numerical approach and its applicability to the evolution of salt structures in the Pricaspian basin. Tectonophysics, 387, 81-103. https://doi.org/10.1016/j.tecto.2004.06.006

Jackson, M. P. A., \& Hudec, M. R. (2017). Salt tectonics: Principles and practise (p. 515). Cambridge University Press.

Jennette, D. C., Garfield, T. R., Mohrig, D. C., \& Cayley, G. T. (2000). The interaction of shelf accommodation, sediment supply and sea level in controlling the facies, architecture and sequence stacking patterns of the Tay and Forties/Sele basin- floor fans, Central North Sea. In P. Weimer, R. M. Slatt, J. Coleman, N. C. Rosen, H. Nelson, A. H. Bouma, M. J. Styzen, \& D. T. Lawrence (Eds.), Deep water reservoirs of the world. GCSSEPM Foundation 20th Annual Bob F. Perkins Research Conference (pp. 402-421).

Jones, I. F., \& Davison, I. (2014). Seismic imaging in and around salt bodies. Interpretation, 2, 1-20. https://doi.org/10.1190/ INT-2014-0033.1

Kane, I. A., Mcgee, D. T., \& Jobe, Z. R. (2012). Halokinetic effects on submarine channel equilibrium profiles and implications for facies architecture: Conceptual model illustrated with a case study from Magnolia Field, Gulf of Mexico. Geological Society, London, Special Publications, 363(1), 289-302.

Katz, O., Morgan, J. K., Aharonov, E., \& Dugan, B. (2014). Controls on the size and geometry of landslides: Insights from discrete element numerical simulations. Geomorphology, 220, 104-113. https://doi. org/10.1016/j.geomorph.2014.05.021

Kernen, R. A., Giles, K. A., Poe, P. L., Gannaway Dalton, C. E., Rowan, M. G., Fiduk, J. C., \& Hearon, T. E. (2020). Origin of the Neoproterozoic rim dolomite as lateral carbonate caprock, Patawarta Salt Sheet, Flinders Ranges, South Australia. Australian Journal of Earth Sciences, 67(6), 815-832. https://doi.org/10.1080/08120 099.2019.1588695

Kernen, R. A., Giles, K. A., Rowan, M. G., Lawton, T. F., \& Hearon, T. E. (2012). Depositional and Halokinetic-Sequence Stratigraphy of the Neoproterozoic Wonoka Formation Adjacent to Patawarta
Allochthonous Salt Sheet, Central Flinders Ranges, South Australia. In G. I. Alsop, S. G. Archer, A. J. Hartley, N. T. Grant, \& R. Hodgkinson (Eds.), Salt tectonics, sediments and prospectivity (Vol. 363, pp. 81-105). Geological Society, London, Special Publications.

Kilhams, B. A., Morton, A., Borella, R., Wilkins, A., \& Hurst, A. (2014). Understanding the provenance and reservoir quality of the Sele Formation sandstones of the UK Central Graben utilizing detrital garnet suites. In R. A. Scott, H. R. Smyth, A. C. Morton, \& N. Richardson (Eds.), Sediment provenance studies in hydrocarbon exploration and production (Vol. 386, pp. 129-142). Geological Society, London, Special Publications.

Kneller, B. C., \& Mccaffrey, W. D. (1999). Depositional effects of flow non-uniformity and stratification within turbidity currents approaching a bounding slope: Deflection, reflection and facies variation. Journal of Sedimentary Research, 69, 980-991. https://doi. org/10.2110/jsr.69.980

Koestler, A. G., \& Ehrmann, W. U. (1991). Description of brittle extensional features in chalk on the crest of a salt ridge (NW Germany). In A. M. Roberts, G. Yielding, \& B. Freeman (Eds.), The geometry of normal faults (Vol. 56, pp. 113-123). Geological Society, London, Special Publications.

Koyi, H. (1998). The shaping of salt diapirs. Journal of Structural Geology, 20, 321-338. https://doi.org/10.1016/S0191 -8141(97)00092-8

Lerche, I., \& Petersen, K. (1995). Salt and sediment dynamics (p. 336). CRC Press.

Li, S. Y., \& Urai, J. L. (2016). Rheology of rock salt for salt tectonics modelling. Petroleum Science, 13, 712-724.

Liu, X., \& Galloway, W. E. (1997). Quantitative determination of tertiary sediment supply to the North Sea Basin. AAPG Bulletin, 81(9), 1482-1509.

Longshaw, S. M., Turner, M. J., \& Finch, E. (2012). Visualizing a spherical geological discrete element model of fault evolution. In Theory and practice of computer graphics - Eurographics UK Chapter Proceedings (pp. 77-84). https://doi.org/10.2312/LocalChapterEve nts/TPCG/TPCG12/077-084.

Longshaw, S. M., Turner, M. J., Finch, E., \& Gawthorpe, R. (2009). Discrete element modelling using a parallelised physics engine. In Theory and practice of computer graphics - Eurographics UK Chapter Proceedings (pp. 207-214). https://doi.org/10.2312/Local ChapterEvents/TPCG/TPCG09/207-214.

Lu, C.-Y., Tang, C.-L., Chan, Y.-C., Hu, J.-C., \& Chi, C.-C. (2014). Forecasting landslide hazard by the 3D discrete element method: A case study of the unstable slope in the Lushan hot spring district, central Taiwan. Engineering Geology, 183, 14-30. https://doi. org/10.1016/j.enggeo.2014.09.007

Luo, G., Hudec, M. R., Flemmings, P. B., \& Nikolinakou, M. A. (2017). Deformation, stress, and pore pressure in an evolving suprasalt basin. Solid Earth, 122(7), 5663-5690. https://doi.org/10.1002/2016J B013779

Luo, G., Nikolinakou, M. A., Flemings, P. B., \& Hudec, M. R. (2012). Geomechanical modeling of stresses adjacent to salt bodies: Part 1 - Uncoupled models. AAPG Bulletin, 96(1), 43-64. https://doi. org/10.1306/04111110144

Madof, A. S., Christie-Blick, N., \& Anders, M. H. (2009). Stratigraphic controls on a salt-withdrawal intraslope minibasin, north-central Green Canyon, Gulf of Mexico: Implications for misinterpreting sea level change. AAPG Bulletin, 93, 535-561. https://doi. org/10.1306/12220808082 
Maia da Costa, A., M da Costa, P., Udebhulu, O., Cabral Azevedo, R., Ebecken, F. F., Miranda, A. C. O., De Eston, M. S., De Tomi, G., Meneghini, R. J., Nishimoto, K., Ruggiere, F., Malta, E., Élis Rocha Fernandes, M., Brandão, C., \& Breda, A. (2019). Potential of storing gas with high $\mathrm{CO}_{2}$ content in salt caverns built in ultra-deep water in Brazil. Greenhouse Gas Science and Technology, 9, 79-94.

Mannie, A. S., Jackson, C.-A.-L., \& Hampson, G. J. (2014). Shallowmarine reservoir development in extensional diapir-collapse minibasins: An integrated subsurface case study from the Upper Jurassic of the Cod terrace, Norwegian North Sea. AAPG Bulletin, 98, 2019-2055.

Mannie, A. S., Jackson, C.-A.-L., Hampson, G. J., \& Fraser, A. J. (2016). Tectonic controls on the spatial distribution and stratigraphic architecture of a net-transgressive shallow-marine synrift succession in a salt-influenced rift basin: Middle to Upper Jurassic, Norwegian Central North Sea. Journal of the Geological Society, 173, 901-915. https://doi.org/10.1144/jgs2016-033

Martín-Chivelet, J., Breastegui, X., Rosales, I., Vera, J. A., Vilas, L., Caus, R., Greafe, K.-I., Sergua, M., Puig, C., Mas, R., Robles, S., Floquet, M., Quesada, S., Ruiz-Ortiz, P. A., Fregenal-Martinez, M. A., Salas, R., Garcia, A., Martin-Algaraara, A., Arias, C., ... Ortega, F. (2002). Cretaceous. In W. Gibbons \& T. Moreno (Eds.), The geology of Spain (pp. 255-292). Geological Society, London, Special Publications.

Mattson, A. G., Royhan Gani, M., Roesler, T., Gani, N. D., \& Ford, J. T. (2020). 3D mapping of intruding salt bodies in the subsurface of the Gulf of Mexico using 3D seismic data. Results in Geophysical Sciences, 1-4, 1-4.

Mayall, M., Lonergan, L., Bowmn, A., James, S., Milles, K., Primmer, T., Pope, D., Rogers, L., \& Skeene, R. (2010). The response of turbidite slope channels to growth-induced seabed topography. $A A P G$ Bulletin, 94, 1011-1030. https://doi.org/10.1306/01051009117

Mora, P., \& Place, D. (1993). A lattice solid model for the nonlinear dynamics of earthquakes. International Journal of Modern Physics, 4, 1059-1074. https://doi.org/10.1142/S0129183193000823

Mora, P., \& Place, D. (1994). Simulation of the frictional stick-slip instability. Pure Applied Geophysics, 143, 61-87. https://doi. org/10.1007/BF00874324

Nikolinakou, M. A., Flemmings, P. B., \& Hudec, M. R. (2014a). Modelling stress evolution around a rising diaper. Marine and Petroleum Geology, 51, 230-238.

Nikolinakou, M. A., Flemmings, P. B., \& Hudec, M. R. (2014b). Comparison of evolutionary and static modelling of stresses around a salt diaper. Marine and Petroleum Geology, 57, 537-545.

Nikolinakou, M. A., Heidari, M., Flemmings, P. B., \& Hudec, M. R. (2018). Geomechanical modelling of pore pressure in evolving salt systems. Marine and Petroleum Geology, 93, 272-286.

Nikolinakou, M. A., Heidari, M., Hudec, M. R., \& Flemings, P. B. (2017). Initiation and growth of salt diapirs in tectonically stable settings: Upbuilding and megaflaps. AAPG Bulletin, 101(6), 887905. https://doi.org/10.1306/09021615245

Nikolinakou, M. A., Luo, G., Hudec, M. R., \& Flemings, P. B. (2012). Geomechanical modeling of stresses adjacent to salt bodies: Part 2 - Poroelastoplasticity and coupled overpressures. AAPG Bulletin, 96(1), 65-85. https://doi.org/10.1306/04111110143

Oluboyo, A. P., Gawthorpe, R. L., Bakke, K., \& Hadler-Jacobsen, F. (2014). Salt tectonic controls on deep-water turbidite depositional systems: Miocene, southwestern Lower Congo Basin, offshore Angola. Basin Research, 26, 597-620. https://doi.org/10.1111/bre.12051
Oreskes, N., Shrader-Frechette, K., \& Beltix, K. (1994). Verification, validation, and confirmation of numerical models in the earth sciences. Science, 263, 641-646. https://doi.org/10.1126/scien ce.263.5147.641

Peel, F. J. (2014). How do salt withdrawal minibasins form? Insights from forward modelling, and implications for hydrocarbon migration. Tectonophysics, 630, 222-235. https://doi.org/10.1016/j. tecto.2014.05.027

Peel, F. J., Hudec, M. R., \& Weijermars, R. (2020). Salt diapir downbuilding: Fast analytical models based on rates of salt supply and sedimentation. Journal of Structural Geology, 141, 104202. https:// doi.org/10.1016/j.jsg.2020.104202

Peeters, S., Asschert, A., \& Werweij, H. (2018). Towards a better understanding of the highly overpressured Lower Triassic Bunter reservoir rocks in the Terschelling Basin. In B. Kilhams, P. A. Kulka, S. Mazur, T. McKie, H. F. Mijnlieff, \& K. van Ojik (Eds.), Mesozoic resource potential in the southern Permian Basin (Vol. 469, pp. 223-236). Geological Society, London, Special Publications.

Pichel, L. M., Finch, E., \& Gawthorpe, R. L. (2019). The impact of presalt rift topography on salt tectonics: A discrete-element modeling approach. Tectonics, 38, 1466-1488. https://doi.org/10.1029/2018T $\mathrm{C} 005174$

Pichel, L. M., Finch, E., Huuse, M., \& Redfern, J. (2017). The influence of shortening and sedimentation on rejuvenation of salt diapirs: A new discrete-element modelling approach. Journal of Structural Geology, 104, 61-79. https://doi.org/10.1016/j.jsg.2017.09.016

Pichel, L. M., \& Jackson, C.-A.-L. (2020). Four-dimensional variability of composite halokinetic sequences. Basin Research, 32, 1277-1299.

Poliakov, A. N. B., Van Belan, R., Podladchikov, Y., Daudre, B., Cloetingh, S., \& Talbot, C. (1993). Numerical analysis of how sedimentation and redistribution of surficial sediments affects salt diapirism. Tectonophysics, 226, 199-216. https://doi. org/10.1016/0040-1951(93)90118-4

Poprawski, Y., Basile, C., Agrirrezabala, L. M., Jaillard, E., Gaudin, M., \& Jacquin, T. (2014). Sedimentary and structural record of the Albian growth of the Bakio salt diapir (the Basque Country, northern Spain). Basin Research, 26, 746-766. https://doi.org/10.1111/ bre.12062

Poprawski, Y., Basile, C., Jaillard, E., Gaudin, M., \& Lopez, M. (2016). Halokinetic sequences in carbonate systems: An example from the Middle Albian Bakio Breccias Formation (Basque Country, Spain). Sedimentary Geology, 334, 34-52.

Pratson, L. F., \& Ryan, W. B. F. (1994). Pliocene to recent infilling and subsidence of intraslope basins offshore Louisiana. American Association of Petroleum Geologists Bulletin, 78, 1483-1506.

Prélat, A., Hodgson, D. M., \& Flint, S. S. (2009). Evolution, architecture and hierarchy of distributary deep-water deposits: A high-resolution outcrop investigation from the Permian Karoo Basin, South Africa. Sedimentology, 56, 2132-2154. https://doi. org/10.1111/j.1365-3091.2009.01073.x

Puelles, P., Ábalos, B., García de Madinabeitia, S., Sánches-Lorda, M. E., Fernández-Armas, S., \& Gil Ibarguchi, J. I. (2014). Provenance of quartz-rich metamorphic tectonite pebbles from the 'Black Flysch' (W Pyrenees, N Spain): An EBSD and detrital zircon LA-ICP-MS study. Tectonophysics, 632, 123-137. https://doi.org/10.1016/j. tecto.2014.06.004

Ribes, C., Kergaravat, C., Bonnel, C., Crumeyrolle, P., Callot, J.-P., Poisson, A., Temiz, H., \& Ringenbach, J.-C. (2015). Fluvial sedimentation in a salt-controlled mini-basin: Stratal patterns and facies 
assemblages, Sivas Basin, Turkey. Sedimentology, 62, 1513-1545. https://doi.org/10.1111/sed.12195

Ribes, C., Kergaravat, C., Crumeyrolle, P., Lopez, M., Bonnel, C., Poisson, A., Kavak, K. S., Callot, J.-P., \& Ringenbach, J.-C. (2017). Factors controlling stratal pattern and facies distribution of fluvio-lacustrine sedimentation in the Sivas mini-basins, Oligocene (Turkey). Basin Research, 29(S1), 596-621. https://doi.org/10.1111/bre.12171

Rider, M., \& Kennedy, M. (2018). The geological interpretation of well $\operatorname{logs}(432$ p.). Bell and Ball.

Riding, R. (2002). Structure and composition of organic reefs and carbonate mud mounds: Concepts and categories. Earth-Science Reviews, 58, 163-231. https://doi.org/10.1016/S0012-8252(01)00089-7

Roca, E., Ferrer, O., Rowan, M. G., Muñoz, J. A., Butillé, M., Giles, K. A., Arbués, P., \& de Matties, M. (2021). Salt tectonics and controls on halokinetic-sequence development of an exposed deepwater diapir: The Bakio Diapir, Basque-Cantabrian Basin, Pyrenees. Marine and Petroleum Geology, 123, 104770. https://doi.org/10.1016/j. marpetgeo.2020.104770

Rodriguez, C. R., Jackson, C.-A.-L., Bell, R. E., Rotevatn, A., \& Francis, M. (2020). Deep-water reservoir distribution on a salt-influenced slope, Santos Basin, offshore Brazil. AAPG Bulletin, online early.

Rodriguez, C. R., Jackson, C.-A.-L., Rotevatn, A., Bell, R. E., \& Francis, M. (2018). Dual tectonic-climatic controls on salt giant deposition in the Santos Basin, offshore Brazil. Geosphere, 14, 215-242. https:// doi.org/10.1130/GES01434.1

Roelofse, C., Alves, T. M., Gafeira, J., \& Omosanya, K. O. (2019). An integrated geological and GIS-based method to assess caprock risk in mature basins proposed for carbon capture and storage. International Journal of Greenhouse Gas Control, 80, 103-122. https://doi.org/10.1016/j.ijggc.2018.11.007

Roma, M., Ferrer, O., Roca, E., Pla, O., Escosa, F. O., \& Butillé, M. (2018). Formation and inversion of salt-detached ramp-syncline basins. Results from analog modeling and application to the Columbrets Basin (Western Mediterranean). Tectonophysics, 745, 214-228.

Rowan, M. G., \& Giles, K. A. (2021). Passive versus active salt diapirism. AAPG Bulletin, 105(1), 53-63.

Rowan, M. G., Lawton, T. F., Giles, K. A., \& Ratliff, R. A. (2003). Nearsalt deformation in La Popa basin, Mexico, and the northern Gulf of Mexico: A general model for passive diapirism. AAPG Bulletin, 87(5), 733-756. https://doi.org/10.1306/01150302012

Sadler, P. (1981). Sediment accumulation rates and the completeness of stratigraphic sections. The Journal of Geology, 89(5), 569-584. https://doi.org/10.1086/628623

Saura, E., Ardèvol i Oró, L., Teixell, A., \& Vergés, J. (2016). Rising and falling diapirs, shifting depocenters, and flap overturning in the Cretaceous Sopeira and Sant Gervàs subbasins (Ribagorça Basin, southern Pyrenees). Tectonics, 35, 638-662. https://doi. org/10.1002/2015TC004001

Schöpfer, M. P. J., Childs, C., \& Walsh, J. J. (2006). Localisation of normal faults in multilayer sequences. Journal of Structural Geology, 28, 816-833. https://doi.org/10.1016/j.jsg.2006.02.003

Schultz-Ela, D. D., Jackson, M. P. A., \& Vendeville, B. C. (1993). Mechanics of active salt diapirism. Tectonophysics, 228, 275-312. https://doi.org/10.1016/0040-1951(93)90345-K

Scott, E. D., Gelin, F., Jolley, S. J., Leenartis, E., Sadler, S. P., \& Elsinger, R. J. (2010). Sedimentological control of fluid flow in deep marine turbidite reservoirs: Pierce Field, UK Central North Sea. In S. J. Jolley, Q. J. Fisher, R. B. Ainsworth, P. J. Vrolijk, \& S. Delisle (Eds.), Reservoir compartmentalization (Vol. 347, pp. 113132). Geological Society, London, Special Publications.
Sellier, N., \& Vendeville, B. C. (2009). Gravitational salt tectonics triggered by deposition of turbiditic lobes: A new experimental modeling approach with applications to salt tongues in the U.S. Gulf of Mexico. AAPG Search and Discovery, Article \#40478.

Soutter, E. L., Bell, D., Cumberpatch, Z. A., Ferguson, R. A., Kane, I. A., Spychala, Y. T., \& Eggenhuisen, J. (2021). The effect of topographic orientation on confined turbidity currents and their deposits. Frontiers in Earth Science. https://www.frontiersin.org/artic les/10.3389/feart.2020.540633/full.

Soutter, E. L., Kane, I. A., Fuhrmann, A., Cumberpatch, Z. A., \& Huuse, M. (2019). The stratigraphic evolution of onlap in clastic deep-water systems: Autogenic modulation of allogenic signals. Journal of Sedimentary Research, 89(10), 890-917.

Spiers, C. J., Schutjens, P. M. T. M., Brzesowsky, R. H., Peach, C. J., Liezenberg, J. L., \& Zwart, H. J. (1990). Experimental determination of constitutive parameters governing creep of rocksalt by pressure solution. Geological Society, London, Special Publications, 54, 215-227. https://doi.org/10.1144/GSL.SP.1990.054.01.21

Stricker, S., Jones, S. J., Meadows, N., \& Bowen, L. (2018). Reservoir quality of fluvial sandstone reservoirs in salt-walled mini-basins: An example from the Seagull field, Central Graben, North Sea, UK. Petroleum Science, 15, 1-27. https://doi.org/10.1007/s1218 2-017-0206-X

Sylvester, Z., Cantelli, A., \& Pirmez, C. (2015). Stratigraphic evolution of intraslope minibasins: Insights from surface-based model. $A A P G$ Bulletin, 99, 1099-1129. https://doi.org/10.1306/01081514082

Sylvester, Z., Deptuck, M. E., Prather, B. E., Primez, C., \& O’Byrne, C. (2012). Seismic stratigraphy of a shelf-edge delta and linked submarine channels in the northeastern Gulf of Mexico. SEPM Special Publication, 99, 31-59.

Teixell, A., Barnalos, A., Rosales, I., \& Arboleya, M.-L. (2017). Structural and facies architecture of a diapir-related carbonate minibasin (lower and middle Jurassic, High Atlas, Morocco). Marine and Petroleum Geology, 81, 334-360. https://doi.org/10.1016/j. marpetgeo.2017.01.003

Tenzer, R., \& Gladkikh, V. (2014). Assessment of density variations of marine sediments with ocean and sediment depths. The Scientific World Journal, 2014, 1-9. https://doi.org/10.1155/2014/823296

Thoeni, K., Giacomini, A., Lambert, C., Sloan, S. W., \& Carter, J. P. (2014). A 3D discrete element modelling approach for rockfall analysis with drapery systems. International Journal of Rock Mechanics and Mining Sciences, 68, 107-119. https://doi.org/10.1016/j. ijrmms.2014.02.008

Trusheim, F. (1960). Mechanism of salt migration in Northern Germany. AAPG Bulletin, 44, 1519-1540.

Tvedt, A. B. M., Rotevatn, A., \& Jackson, C.-A.-L. (2016). Supra-salt normal fault growth during the rise and fall of a diapir: Perspectives from 3D seismic reflection data, Norwegian North Sea. Journal of Structural Geology, 91, 1-26. https://doi.org/10.1016/j. jsg.2016.08.001

Tvedt, A. B. M., Rotevatn, A., Jackson, C.-A.-L., Fossen, H., \& Gawthorpe, R. L. (2013). Growth of normal faults in multilayer sequences: A 3D seismic case study from the Egersund Basin, Norwegian North Sea. Journal of Structural Geology, 55, 1-20. https://doi.org/10.1016/j.jsg.2013.08.002

Van Bergen, F., \& De Leeuw, C. S. (2001). Salt cementation of reservoir rocks near salt domes in the Netherlands North Sea Area - A new mechanism. Conference Proceedings, 63rd EAGE Conference and Exhibition, June. https://www.earthdoc.org/content/paper s/10.3997/2214-4609-pdb.15.P607 
Vendeville, B. C., Ge, H., \& Jackson, M. P. A. (1995). Scale models of salt tectonics during basement-involved extension. Petroleum Geoscience, 1, 179-183. https://doi.org/10.1144/petgeo.1.2.179

Vendeville, B. C., \& Jackson, M. P. A. (1992). The rise of diapirs during thin-skinned extension. Marine and Petroleum Geology, 9, 331353. https://doi.org/10.1016/0264-8172(92)90047-I

Wang, X., Luthi, S. M., Hodgson, D. M., Sokoutis, D., Willingshofer, E., \& Groenenberg, R. M. (2017). Turbidite stacking patterns in saltcontrolled minibasins: Insights from integrated analogue models and numerical fluid flow simulations. Sedimentology, 64, 530-552. https://doi.org/10.1111/sed.12313

Warren, J. (1999). Evaporites: Their evolution and economics (438 p.). Blackwell Science.

Warren, J. (2006). Evaporites: Sediments, resources, and hydrocarbons (1035 p.). Springer.

Warren, J. (2016). Evaporites: A geological compendium (1813 p.). Springer.

Whitman, J. M., \& Davies, T. A. (1979). Cenozoic oceanic sedimentation rates: How good are the data? Marine Geology, 30, 269-284.

Wu, N., Jackson, C.-A.-L., Johnson, H. D., Hodgson, D. M., \& Nugraha, H. D. (2020). Mass-transport complexes (MTCs) document subsidence patterns in a northern Gulf of Mexico salt minibasin. Basin Research, 32(6), 1300-1327.

Zhao, J. J., Xiao, J. G., Lee, M. L., \& Ma, Y. T. (2016). Discrete element modelling of a mining-induced rock slide. SpringerPlus, 5, Article number 1633.

Zhu, H. P., Zhou, Z. Y., Yang, R. Y., \& Yu, A. B. (2008). Discrete particle simulation of particulate systems: A review of major applications and findings. Chemical Engineering Science, 63, 5728-5770.

\section{SUPPORTING INFORMATION}

Additional Supporting Information may be found online in the Supporting Information section.

How to cite this article: Cumberpatch ZA, Finch E, Kane IA, et al. Halokinetic modulation of sedimentary thickness and architecture: A numerical modelling approach. Basin Res. 2021;00:1-33. https://doi. org/10.1111/bre.12569 